\title{
Las fuentes de información sobre el empleo público en España: revisión, diagnóstico y propuestas de cambio
}

\section{The sources of information on public employment in Spain: review, diagnosis and proposals for change}

\author{
José María de Luxán Meléndez \\ Centro de Estudios Políticos y Constitucionales (España) \\ ORCID: https://orcid.org/0000-0002-6514-9442 \\ jmluxan@cepc.es
}

\begin{abstract}
NOTA BIOGRÁFICA
Doctor en Ciencia Política por la Universidad Complutense de Madrid. Administrador Civil del Estado. Profesor Asociado de Ciencia Política y de la Administración en la Universidad Complutense de Madrid. Ha sido Subsecretario del Ministerio de Trabajo y miembro del Consejo de Universidades. Actualmente es vocal asesor del Centro de Estudios Políticos y Constitucionales.
\end{abstract}

\section{RESUMEN}

Para describir el tamaño del empleo público y el volumen del gasto de personal de las administraciones públicas es usual utilizar como referencia una pluralidad de fuentes estadísticas basadas en registros administrativos, y también emplear los datos de Contabilidad Nacional y las estadísticas del mercado de trabajo. Esta diversidad de fuentes y de metodologías conduce necesariamente a una gran disparidad de resultados. En este trabajo en el ámbito del empleo y del gasto de personal se revisa el Inventario de Operaciones Estadísticas sobre las Administraciones Públicas. Y se analiza que la imagen que se construye sobre las retribuciones o sobre el tamaño y características del empleo público y de sus remuneraciones varía en función de la estadística a la que se acuda.

Se presentan nueve figuras sobre el número de empleados, el empleo femenino, el peso del empleo de las Comunidades Autónomas, la temporalidad en el empleo público, y el gasto de personal. Y por último, se plantean un conjunto de propuestas para mejorar la transparencia y la eficiencia del sistema de información del empleo y del gasto de personal en el Sector Público.

\section{PALABRAS CLAVE}

Empleo público; gastos de personal; políticas públicas; estadísticas de empleo.

\begin{abstract}
In order to describe the size of public employment and staff expenditure of the Spanish Public Administrations it is common to use several statistical sources based on administrative registers, data from National Accounting and also labor market statistics. This variety of sources and methodologies has led to a wide disparity in results. This article reviews and analyzes the Statistical Operations Inventory on Public Administrations to demonstrate that the image built on those salaries, size, characteristics of public employment and its remuneration, depends on the statistic used.
\end{abstract}

For this purpose, we show nine figures that measure number of employees, female employment, weight of public employment in Spain's Autonomous Communities, level of temporality, and the total personnel 
GAPP. Nueva Época - N. ${ }^{\circ}$ 23, mayo-octubre 2020 - ISSN: 1989-8991 - DOI: 10.24965/gapp.i23.10686 - [Págs. 20-44]

Las fuentes de información sobre el empleo público en España: revisión, diagnóstico y propuestas de cambio

José María de Luxán Meléndez

expenditure. In the last section we listed a set of proposals to improve transparency and efficiency of the Spanish information system on employment and staff expenses in the Public sector.

\section{KEYWORDS}

Public employment; personnel expenses; public policies; employment statistics.

\section{SUMARIO}

1. INTRODUCCIÓN. 2. EL EMPLEO PÚBLICO, REVISIÓN DE FUENTES. 2.1. LA ENCUESTA DE POBLACIÓN ACTIVA. 2.2. EL BOLETÍN ESTADÍSTICO DEL PERSONAL AL SERVICIO DE LAS ADMINISTRACIONES PÚBLICAS (BEPSAP). 3. LAS RETRIBUCIONES DE LOS EMPLEADOS PÚBLICOS, REVISIÓN DE FUENTES. 3.1. LA ESTADÍSTICA SALARIAL DE LA ENCUESTA DE POBLACIÓN ACTIVA (EPA). 3.2. CONTABILIDAD NACIONAL. 3.3. LA ESTADÍSTICA DE LAAGENCIA TRIBUTARIA. 4. COMPARACIÓN DE FUENTES. 4.1. EL NÚMERO DE EMPLEADOS. 4.2. EL EMPLEO FEMENINO. 4.3. COMUNIDADES AUTÓNOMAS. 4.4. TEMPORALIDAD. 4.5. EL GASTO DE PERSONAL. 5. DISCUSIÓN Y PROPUESTAS. 6. REFERENCIAS BIBLIOGRÁFICAS.

\section{INTRODUCCIÓN ${ }^{1}$}

Para describir el tamaño y la evolución del empleo y del gasto de personal de las administraciones públicas es usual utilizar como referencia fuentes estadísticas basadas en operaciones administrativas, y también, en el campo de las políticas públicas es habitual emplear los datos de Contabilidad Nacional (CN) y las estadísticas del mercado de trabajo del Instituto Nacional de Estadística (INE).

Como era de esperar la pluralidad de fuentes con metodologías diferentes conduce a resultados dispares que pueden dar una imagen de falta de transparencia o de ineficiencia en la gestión de las políticas públicas y en especial en la política de empleo público. A menudo en diversos medios se resaltan las diferencias entre unas y otras estadísticas, por ejemplo ABC señalaba que «la incógnita perenne de cuántos empleados públicos tiene España ha sido un quebradero de cabeza recurrente en los últimos años, ante la ausencia de una estadística única» (ABC, 08-05-2018). Y también El País afirmaba que «como ejemplo de la desorganización existente el ministro de Exteriores... ha explicado que el Ejecutivo no sabe...cuántos funcionarios tiene en las distintas representaciones en el extranjero» (El País, 01-03-2013). Diversidad y lagunas de información que en ocasiones se ha percibido por la administración pública y por los agentes sociales como un problema. «Hacienda -entonces responsable de función pública- planea acabar con esta dispersión de datos: fuentes del Ministerio confirman que modificará el actual Registro Central... La medida no se adoptará en breve y tomará su tiempo, describen estas fuentes» (ABC, 08-05-2018). Y en otras ocasiones no es un problema, como parece desprenderse del informe de la Comisión para la Reforma de la Administración (CORA) en el que, indicando las fuentes, en páginas sucesivas se utilizan cifras de la Encuesta de Población Activa (EPA) -3.220.600 de empleados públicos-, y aparentemente con la misma validez, datos -2.183.780- del Boletín Estadístico del personal al servicio de la administración pública (CORA, 2013, págs. 43-48).

En su estudio pionero de 1974 sobre los efectivos de la Administración, Junqueras, González-Haba, Iparraguirre, y Santamaría pusieron de manifiesto la falta de información estadística de la década de 1960, en la que los «cálculos y estadísticas sobre el número de funcionarios del Estado son sumamente heterogéneos, al presentar entre sí notables disparidades y diferencias» (Junquera, et al., 1974, pág. 15) y a partir de los Presupuestos y del Registro de Personal abordaron una tarea de reconstrucción de la evolución del número de empleados de Administración Civil según la cual estimaron que entre 1954 y 1973, pasaron de 295.149 a 463.080 (Junquera, et al., 1974, pág. 40).

Olías de Lima destaca que «el número de funcionarios públicos es una cuestión de continuo debate, ya que si, por una parte, está claro que existe una correlación positiva entre el bienestar o el grado de desarrollo de un país y el número de sus empleados públicos, por otra se tiende a infravalorar el papel de los servidores públicos en la consecución de dichos logros» (Olías de Lima, 1995, pág. 44).

La cuestión del número de empleados públicos fue inmediatamente advertida por la Ciencia de la Administración, Baena del Alcázar señalaba en 1985 la dificultad para conocer «el número de funcionarios al

1 Una primera versión de este artículo ha sido mejorada con los comentarios críticos de Ana Benito, Blanca Olías de Lima, José Luis de Ossorno, y Demetrio Vicente, a los que agradezco sus observaciones, aunque sólo soy yo responsable del resultado. 
servicio de las Comunidades Autónomas» (Baena del Alcázar, 1985, pág. 455, nota 38), para concluir que «haciendo una estimación general (y no manejando cifras ciertas) puede fijarse el número total de funcionarios españoles en 900.000» (Baena del Alcázar, 1985, pág. 456), sin incluir a "contratados administrativos y laborales ni al personal de las empresas públicas» (Baena del Alcázar, 1985, pág. 456, nota 41). Y Olías de Lima subrayó que «hasta la creación del Registro central de Personal, en 1984, se desconocía el número de funcionarios públicos existentes en nuestro país» (Olías de Lima, 1995, pág. 45) y recoge que de acuerdo con el Ministerio de Administraciones Públicas, responsable del Registro, para 2005 eran 2.387.414 el total de empleados públicos de todas las administraciones y de todas las categorías (Olías de Lima, 2006, pág. 182).

En los últimos años para medir la evolución y las características del empleo público, Montesinos, Pérez y Ramos optan por la información de la Encuesta de Población Activa por cuatro razones:

«En primer lugar, porque permite cubrir todo el período de crisis y posterior ajuste fiscal, a diferencia de los datos que proporciona la $\mathrm{CN}$ relativos al número de empleados de las AAPP, que se publican con mucho retraso. En segundo lugar, porque permite identificar el sector AAPP, frente a otros indicadores que mezclan elementos "de mercado" y "de no mercado", como son las estadísticas relativas a los sectores APEDUSAN² de la CN, que publica el INE, y el registro de afiliados a la Seguridad Social, que publica el Ministerio de Empleo y Seguridad Social. En tercer lugar, por la cobertura más completa del sector AAPP en la EPA en comparación con fuentes alternativas que miden el número de empleados de las AAPP, como es el Registro Central de Personal al Servicio de las AAPP que publica el Ministerio de Hacienda y AAPP. Finalmente, porque la disponibilidad de microdatos individuales de la EPA permite enriquecer la discusión y el análisis» (Montesinos, Perez, \& Ramos, 2014, págs. 7-12).

Mientras que desde otro punto de vista Arenilla y Delgado concluyen que «el análisis de cada una de las fuentes que suministran los datos de empleo público permite inferir, pese a las dificultades comparativas, que aunque no se trata de la fuente más completa, sí resulta la más fiable, desde una perspectiva metodológica y sistemática, el Boletín Estadístico del Personal al Servicio de las Administraciones Públicas, del Registro Central de Personal» (Arenilla \& Delgado, 2014, pág. 302).

Sobre las retribuciones y el gasto de personal en el sector público en 2016 el estudio de Hernández de Cos, Moral-Benito, y Pérez, utilizan de referencia los datos de CN, de la E PA y en algún caso del Boletín Estadístico del personal al servicio de la administración pública (Hernádez de Cos, Moral-Benito, \& Pérez, 2016). En la misma línea 2017 Martínez y Pérez para analizar la evolución del empleo de las administraciones públicas optan por emplear datos de CN y de la EPA (Martínez \& Pérez, 2017).

En otro ámbito Jordana y Ramió junto utilizan la EPA para presentar la evolución del número de asalariados del sector público por sexo entre 1976 y 2001, mientras que para la evolución histórica del número de empleados de los ministerios entre 1837 y 1975, se basan en los Presupuestos Generales del Estado (Jordana \& Ramió, $2005\left(2{ }^{a}\right)$, págs. 1.003-1.005).

Y por citar un último ejemplo para estudiar la organización interna de un departamento ministerial, Salvador Parrado se refiere a datos del Boletín estadístico del personal al servicio de las Administraciones Públicas (Parrado, 2017, págs. 317-321) mientras que para presentar la evolución de la función pública estatal según el grado de los funcionarios utiliza datos de la Intervención General del Estado (Parrado, 2017, pág. 322).

En este trabajo ${ }^{3}$ se analiza de manera detallada el Inventario de Operaciones Estadísticas ${ }^{4}$ y se comparan las características de las que por la amplitud del colectivo sobre el que se recoge información, extensión de la serie temporal, o información más desagregada, pueden ser más relevantes para el empleo y el gasto del sector público.

Para analizar si la imagen sobre las retribuciones o sobre el tamaño y características del empleo público, varía en función de la estadística a la que se acuda, se detallan cinco casos relevantes que permiten valorar

2 Es la agregación de los sectores «Administración, Defensa y Seguridad Social Obligatoria», «Educación» y «Actividades Sanitarias».

3 Este trabajo sigue la línea de tres anteriores, ampliados y actualizados con datos de 2019: El segundo epígrafe para la comparación de fuentes "Las políticas de empleo público en España (1996-2017): diagnóstico y propuestas para su modernización y eficiencia” (LUXÁN MELÉNDEZ, 2019), y "La ruptura del contrato de lealtad. Evolución del empleo científico-técnico en el Sector Público español" (LUXÁN MELÉNDEZ, 2019b). El tercero epígrafe para la revisión de fuentes "El impacto de la crisis en las retribuciones del Sector Público" (LUXÁN MELÉNDEZ, 2016).

4 «El Inventario de Operaciones Estadísticas es un repertorio de las operaciones estadísticas llevadas a cabo por la Administración del Estado (INE, departamentos ministeriales, Banco de España y Consejo General del Poder Judicial), en el que se presenta, con fines de coordinación, homogeneización e integración, la forma en que se realizan las estadísticas» (INSTITUTO NACIONAL DE ESTADÍSTICA (INE), 2017, pág. 1). 
la distorsión que pueda haber entre las distintas fuentes y la posibilidad de cada una de ellas para realizar comparaciones sectoriales o internacionales. Para ello se presentan nueve figuras sobre el número de empleados, el empleo femenino, y el peso del empleo de las Comunidades Autónomas, la temporalidad en el empleo público, y el gasto de personal.

Y por último en la discusión se plantean un conjunto de propuestas para articular un modelo integral de información del empleo y de los gastos de personal del sector público.

\section{EL EMPLEO PÚBLICO, REVISION DE FUENTES}

Desde el punto de vista del empleo el sector público ${ }^{5}$ que incluye la Administración General del Estado, las Administraciones de las Comunidades Autónomas y de las ciudades de Ceuta y Melilla, las Administraciones Locales, y el sector público institucional, integra a los trabajadores de todas las instituciones públicas, que de acuerdo con el Estatuto Básico del Empleado público ${ }^{6}$ pueden ser funcionarios de carrera, funcionarios interinos, personal laboral, ya sea fijo, por tiempo indefinido o temporal, y personal eventual.

El Inventario de Operaciones Estadísticas incluidas en el Plan Estadístico Nacional 2017-2020 agrupa en el sector Administraciones Públicas y asociaciones las estadísticas sobre el personal de las Administraciones Públicas y sus retribuciones; y las estadísticas presupuestarias y fiscales. Además, las estadísticas del Mercado laboral y de las Cuentas económicas son especialmente relevantes por que se incorporan información detallada sobre el ámbito público (Tabla 1).

TABla 1. El empleo público en el INVENTARio de operaciones Estadísticas

\begin{tabular}{|c|c|c|c|}
\hline Sector (tema) & $\begin{array}{l}\text { Subsector } \\
\text { (subtema) }\end{array}$ & $\begin{array}{l}\text { Operaciones más } \\
\text { relevante sobre el empleo } \\
\text { en el ámbito público }\end{array}$ & $\begin{array}{l}\text { Otras operaciones en las que se presenta } \\
\text { información sobre el empleo público }\end{array}$ \\
\hline $\begin{array}{l}\text { Administraciones } \\
\text { públicas y } \\
\text { asociaciones }\end{array}$ & $\begin{array}{l}\text { Personal de } \\
\text { las Adms. } \\
\text { Públicas y sus } \\
\text { retribuciones. }\end{array}$ & $\begin{array}{l}\text { Registro Central de } \\
\text { Personal. Boletín } \\
\text { Estadístico del Personal } \\
\text { al Servicio de las } \\
\text { Administraciones Públicas. }\end{array}$ & $\begin{array}{l}\text { - Efectivos de Personal al Servicio del Sector } \\
\text { Público Estatal. } \\
\text { - Estadística del Personal Civil Funcionario } \\
\text { al Servicio de la Administración Militar. } \\
\text { - Estadística del Personal Civil Laboral al } \\
\text { Servicio de la Administración Militar. } \\
\text { - Estadística del Personal Militar de Carrera } \\
\text { de las Fuerzas Armadas de las Categorías } \\
\text { de Oficial General, Oficial y Suboficial y de } \\
\text { Personal Militar de Carrera del Cuerpo de } \\
\text { la Guardia Civil. } \\
\text { - Estadística del Personal Militar de } \\
\text { Complemento, Militar de Tropa y Marinería } \\
\text { y Reservista. } \\
\text { - Estadística de Convocatorias para el } \\
\text { Ingreso como Militar de Carrera. } \\
\text { - Estadística de Convocatorias para el } \\
\text { Ingreso como Militar de Complemento. } \\
\text { - Estadística de Convocatorias para el } \\
\text { Ingreso como Militar de Tropa y Marinería. } \\
\text { - Estadística de Convocatorias para el } \\
\text { Acceso a Reservista Voluntario. } \\
\text { Estadística del Personal Estatutario al } \\
\text { Servicio de la Administración Militar. }\end{array}$ \\
\hline
\end{tabular}

5 Art. 2 de la Ley 40/2015, de 1 de octubre, de Régimen Jurídico del Sector Público. BOE de 2 de octubre de 2015.

6 La Ley de Régimen Jurídico del sector público y el EBEP excluyen de su ámbito a los que no desempeñan funciones retribuidas en las Administraciones Públicas, y además tengan o no retribuciones también a los titulares de los órganos constitucionales a los que ambas leyes no se refieren directamente, lo que descartaría al Rey; a los miembros de las Cortes Generales, de las Asambleas legislativas de las Comunidades Autónomas, y de las Corporaciones locales; a los miembros del Gobierno, y de los Consejos de Gobierno; a los titulares de los órganos dependientes de las Cortes Generales o de las Asambleas legislativas y a los magistrados del Tribunal Constitucional.

7 Real Decreto 410/2016, de 31 de octubre, por el que se aprueba el Plan Estadístico Nacional 2017-2020. BOE de 18 de noviembre de 2016. 


\begin{tabular}{|c|c|c|c|}
\hline Sector (tema) & $\begin{array}{l}\text { Subsector } \\
\text { (subtema) }\end{array}$ & $\begin{array}{l}\text { Operaciones más } \\
\text { relevante sobre el empleo } \\
\text { en el ámbito público }\end{array}$ & $\begin{array}{l}\text { Otras operaciones en las que se presenta } \\
\text { información sobre el empleo público }\end{array}$ \\
\hline $\begin{array}{l}\text { Mercado Laboral y } \\
\text { Salarios }\end{array}$ & $\begin{array}{l}\text { Mercado } \\
\text { laboral. }\end{array}$ & $\begin{array}{l}\text { - Encuesta de Población } \\
\text { Activa. } \\
\text { - Estadística del Mercado de } \\
\text { Trabajo y Pensiones en las } \\
\text { Fuentes Tributarias. } \\
\text { - Estadística de Afiliación } \\
\text { de Trabajadores a la } \\
\text { Seguridad Social. } \\
\end{array}$ & $\begin{array}{l}\text { - Estadística de Movilidad Laboral y } \\
\text { Geográfica. } \\
\text { - Flujos de la Población Activa. } \\
\text { - Estadística de Cuentas de Cotización a la } \\
\text { Seguridad Social. }\end{array}$ \\
\hline $\begin{array}{l}\text { Cuentas } \\
\text { económicas }\end{array}$ & $\begin{array}{l}\text { Contabilidad } \\
\text { Nacional. }\end{array}$ & $\begin{array}{l}\text { - Contabilidad Nacional } \\
\text { Trimestral: Principales } \\
\text { Agregados (empleo). } \\
\text { - Contabilidad Nacional } \\
\text { Anual: Agregados por } \\
\text { Rama de Actividad } \\
\text { (empleo). } \\
\text { - Cuentas Anuales no } \\
\text { Financieras de los Sectores } \\
\text { Institucionales (síntesis). }\end{array}$ & \\
\hline $\begin{array}{l}\text { Seguridad y } \\
\text { Justicia }\end{array}$ & $\begin{array}{l}\text { Actividad } \\
\text { Judicial. }\end{array}$ & & $\begin{array}{l}\text { - Estadística del Personal Judicial: Jueces y } \\
\text { Magistrados. }\end{array}$ \\
\hline $\begin{array}{l}\text { Investigación } \\
\text { científica y } \\
\text { desarrollo } \\
\text { tecnológico }\end{array}$ & $\begin{array}{l}\text { Recursos } \\
\text { económicos, } \\
\text { personal y } \\
\text { actividades en } \\
\text { I+D. } \\
\end{array}$ & & $\begin{array}{l}\text { - Estadística sobre Actividades en I+D en el } \\
\text { Sector Administración Pública. } \\
\text { - Estadística sobre Actividades en I+D en el } \\
\text { Sector Enseñanza Superior. }\end{array}$ \\
\hline \multirow[t]{2}{*}{$\begin{array}{l}\text { Educación y } \\
\text { Formación }\end{array}$} & $\begin{array}{l}\text { Personal y } \\
\text { aspectos } \\
\text { económicos de } \\
\text { la educación. }\end{array}$ & & $\begin{array}{l}\text { - Estadística de Personal de las } \\
\text { Universidades. }\end{array}$ \\
\hline & $\begin{array}{l}\text { Indicadores, } \\
\text { síntesis y } \\
\text { recopilaciones } \\
\text { en educación. }\end{array}$ & & $\begin{array}{l}\text { - Las Cifras de la Educación en España. } \\
\text { Estadísticas e Indicadores. }\end{array}$ \\
\hline
\end{tabular}

Fuente: Elaboración propia.

El sector público dispone de una pluralidad de fuentes de información estadística sobre el empleo público basadas en registros administrativos como el Registro Central de Personal, y los de la Agencia Tributaria, la Intervención General del Estado o la Seguridad Social, así como en la información que proporciona la Encuesta de Población Activa.

Sobre el volumen y la evolución del empleo público contamos con seis fuentes principales ${ }^{8}$, todas ellas con características (Tabla 2) y resultados diferentes (Figura 1). Por la amplitud de sus series y por el nivel de desagregación, las más relevantes (Tabla 3) son la Encuesta de Población Activa (EPA); y el Boletín Estadístico del Personal al Servicio de las Administraciones Públicas (BEPSAP). Y en segundo lugar la estadística del Mercado de trabajo y pensiones en las fuentes tributarias; y la estadística de la Seguridad Social.

En ningún caso la etiqueta empleo público recoge a los trabajadores, contratados por empresas privadas, que mediante distintas fórmulas realicen toda su actividad exclusivamente y de manera permanente para el Estado, y la desarrollen siempre y completamente en instalaciones de las administraciones públicas.

8 Además publican cifras de empleo público la Mutualidad General de Funcionarios Civiles del Estado el Instituto Social de las Fuerzas Armadas y la Mutualidad General Judicial. Así mismo también incorporan datos de empleo público las estadísticas del Consejo del Poder Judicial, las estadísticas sectoriales de educación, de investigación, y culturales, así como las estadísticas de las Comunidades Autónomas. 
TABla 2. Características de las fuentes estadísticas sobre el empleo publico

\begin{tabular}{|c|c|c|}
\hline \multirow{4}{*}{$\begin{array}{l}\text { Por el colectivo } \\
\text { sobre el que } \\
\text { se recoge } \\
\text { información }\end{array}$} & $\begin{array}{l}\text { Ocupados en la } \\
\text { administración pública, } \\
\text { educación y sanidad. }\end{array}$ & $\begin{array}{l}\text { Contabilidad Nacional -estadística de empleo- (presenta las } \\
\text { cifras agregadas incluyendo los asalariados del sector privado } \\
\text { de educación y sanidad) }\end{array}$ \\
\hline & $\begin{array}{l}\text { Asalariados del sector } \\
\text { público. }\end{array}$ & $\begin{array}{l}\text { - Encuesta de Población Activa. } \\
\text { - Contabilidad Nacional (elaboración de síntesis). } \\
\text { - Mercado de trabajo y pensiones en las fuentes tributarias. }\end{array}$ \\
\hline & $\begin{array}{l}\text { Asalariados del sector } \\
\text { publico en el régimen } \\
\text { general de la Seguridad } \\
\text { Social. }\end{array}$ & - Estadística de la Seguridad Social. \\
\hline & $\begin{array}{l}\text { Empleados } \\
\text { Administraciones } \\
\text { Públicas. }\end{array}$ & $\begin{array}{l}\text { Boletín Estadístico del Personal al Servicio de las } \\
\text { Administraciones Públicas (no incluye algunos colectivos de } \\
\text { empleados públicos) }\end{array}$ \\
\hline \multirow[t]{6}{*}{$\begin{array}{l}\text { Por el origen de } \\
\text { la información }\end{array}$} & \multirow[t]{3}{*}{ Registro administrativo. } & $\begin{array}{l}\text { - Boletín Estadístico del Personal al Servicio de las } \\
\text { Administraciones Públicas (Registro Central de Personal) }\end{array}$ \\
\hline & & - Mercado de trabajo y pensiones en las fuentes tributarias. \\
\hline & & - Estadística de la Seguridad Social. \\
\hline & $\begin{array}{l}\text { Información } \\
\text { administrativa. }\end{array}$ & $\begin{array}{l}\text { - Boletín Estadístico del Personal al Servicio de las } \\
\text { Administraciones Públicas. } \\
\text { - Contabilidad Nacional. }\end{array}$ \\
\hline & Información muestral. & - Encuesta de Población Activa. \\
\hline & Elaboración de síntesis. & - Contabilidad Nacional. \\
\hline \multirow[t]{3}{*}{$\begin{array}{l}\text { Por el ámbito } \\
\text { geográfico }\end{array}$} & En todo el mundo. & $\begin{array}{l}\text { - Boletín Estadístico del Personal al Servicio de las } \\
\text { Administraciones Públicas. }\end{array}$ \\
\hline & Residentes en España. & $\begin{array}{l}\text { - Estadística de la Seguridad Social. } \\
\text { - Encuesta de Población Activa. } \\
\text { - Contabilidad Nacional. }\end{array}$ \\
\hline & En parte de España. & - Mercado de trabajo y pensiones en las fuentes tributarias. \\
\hline \multirow[t]{4}{*}{$\begin{array}{l}\text { Por la referencia } \\
\text { temporal }\end{array}$} & Anuales. & $\begin{array}{l}\text { - Contabilidad Nacional(estadística de empleo y síntesis del } \\
\text { ámbito público) } \\
\text { - Mercado de trabajo y pensiones en las fuentes tributarias (todo } \\
\text { el año). }\end{array}$ \\
\hline & Semestral. & $\begin{array}{l}\text { - Boletín Estadístico del Personal al Servicio de las } \\
\text { Administraciones Públicas (en el día de referencia). }\end{array}$ \\
\hline & Trimestrales. & $\begin{array}{l}\text { - Encuesta de Población Activa (en la semana de referencia) } \\
\text { - Contabilidad Nacional (estadística de empleo). }\end{array}$ \\
\hline & Mensuales. & - Estadística de la Seguridad Social (en el mes de referencia). \\
\hline $\begin{array}{l}\text { Por su empleo } \\
\text { internacional }\end{array}$ & EUROSTAT, OCDE, OIT. & $\begin{array}{l}\text { - Encuesta de Población Activa. } \\
\text { - Contabilidad Nacional. }\end{array}$ \\
\hline
\end{tabular}


La estadística que elabora la Agencia Tributaria ${ }^{9}$ es una explotación de fuentes administrativas, que desde 2015 contiene datos sobre las retribuciones, retenciones, y personas ${ }^{10}$ que a lo largo del año en algún momento han estado vinculadas a las administraciones públicas, lo que incluye a los que están durante todo el año, a los nuevos, no importa en qué momento se incorporan o que tengan un contrato o nombramiento indefinido o temporal, e igualmente a los que también a lo largo del año han dejado por distintitos motivos ${ }^{11}$ de estar en algún momento ligados con la administración. Por su propia naturaleza los resultados (Figura 1) son sensiblemente superiores a cualquier otra fuente.

Contabilidad Nacional ${ }^{12}$ desde 1995 publica información trimestral agregada del empleo en la rama de actividad administración pública, educación y sanidad, que incluye en estos casos también al sector privado, con información sobre el número de personas, puestos de trabajo, puestos de trabajo a tiempo completo y horas trabajadas. Además realiza una estadística de síntesis ${ }^{13}$ que incorpora datos agregados del número de personas empleadas en el sector administraciones públicas, que toma como referencia la EPA, las remuneraciones de los empleados públicos según la Cuenta Nacional de la Intervención General de Administración del Estado, y la estadística del BEPSAP.

La Seguridad Social desde octubre de 2013 publica información desagregada por genero y provincia sobre los empleados públicos, funcionarios o laborales, incluidos en el régimen general de la seguridad social cuyo número se ha incrementado progresivamente como consecuencia de los cambios en el régimen de seguridad social del empleo público ${ }^{14}$. Además pueden obtenerse datos de la Muestra Continua de Vidas Laborales (MCVL) ${ }^{15}$.

\subsection{La Encuesta de Población Activa}

La Encuesta de Población Activa (EPA), recoge información sobre los asalariados del sector público que viven en España. La EPA recoge información de una muestra continua, representativa de la población residente en España, en la que, al igual que para el resto de la sociedad, son los encuestados los que señalan su vinculación laboral referida a la semana en que se realiza cada entrevista.

La EPA que se realiza desde 1964, es una investigación por muestreo ${ }^{16}$ de periodicidad trimestral, dirigida a la población que reside en viviendas familiares del territorio nacional, e incluye a las «personas con trabajo por cuenta ajena o asalariadas que durante la semana de referencia hayan trabajado, incluso de

9 La Agencia Tributaria proporciona una estadística anual que integra datos registrales muy precisos que excluye a las Comunidades Forales. La estadística descansa en la relación de perceptores de rentas que presentan los empleadores y entidades pagadoras de pensiones o de prestaciones por desempleo mediante la Declaración Resumen Anual de Retenciones e Ingresos a Cuenta sobre Rendimientos del Trabajo, de determinadas actividades económicas, premios y determinadas imputaciones de renta (Metodología. Mercado de Trabajo y Pensiones en Las Fuentes Tributarias).

10 Son personas asalariadas las que reciben una contraprestación dineraria en concepto de rendimiento de trabajo, contadas de forma única independientemente de que hayan trabajado para una o varias empresas o entidades (Metodología. Mercado de Trabajo y Pensiones en Las Fuentes Tributarias).

11 Entre los principales motivos se puede relacionar los siguientes: despido, renuncia, fin de contrato, excedencia, sanción, inhabilitación, jubilación, o fallecimiento.

12 Además entre1980 y 2011 Contabilidad nacional cuenta con una serie en la que el empleo público se integra en la rama sector servicios no de mercado.

13 En la última revisión elaborada durante 2019 conforme al proyecto técnico (Instituto Nacional de Estadística, 22 de febrero de 2019) los datos sobre empleo público se extienden hasta 1999 y se actualizan los correspondientes a los años 2011 a 2017 . Los nuevos datos que incluyen 2018 están publicados el 30 de septiembre de 2019. Ingresos y gastos de las administraciones públicas y subsectores https://www.ine.es/dyngs/INEbase/es/operacion.htm?c=Estadistica_C\&cid=1254736177054\&menu=resultados\&secc=12 $54736195668 \& i d p=1254735576581$.

14 El Real Decreto-Ley 13/2010, de 3 de diciembre, de actuaciones en el ámbito fiscal, laboral y liberalizadoras para fomentar la inversión y la creación de empleo, ha establecido como obligatorio el encuadramiento en el Régimen General de la Seguridad Social de todos los funcionarios de nuevo ingreso.

15 «La Muestra Continua de Vidas Laborales (MCVL) es un extracto de datos individuales anonimizados, procedentes de las bases de datos de la Seguridad Social, a los que se añaden otros que se toman del Padrón Continuo Municipal (INE) y del resumen anual de retenciones e ingresos a cuenta del IRPF (Modelo 190) de la AEAT. Los datos corresponden a una muestra de personas seleccionadas al azar entre quienes fueron afiliados o pensionistas de la Seguridad Social durante el último año natural finalizado, o año de referencia. Para cada persona se incluyen tanto datos sobre su relación con la Seguridad Social en dicho año como datos históricos, en la medida en que se conserven en registros informatizados» (Secretaria de Estado de la Seguridad Social, 2018, pág. 1).

16 La muestra inicial es de unas 65.000 familias al trimestre que equivalen a 180.000 personas (INSTITUTO NACIONAL DE ESTADÍSTICA (INE), 2016). 
forma esporádica u ocasional, al menos una hora a cambio de un sueldo, salario u otra forma de retribución conexa, en metálico o en especie ${ }^{17}{ }^{17}$ (Instituto Nacional de Estadística, 2017, pág. 14).

Desde 1976 el INE publica información sobre los asalariados del sector público (Tabla 3), con información desagregada por género, edad, distribución territorial, ocupación profesional ${ }^{18}$, tipo de administración, tipo de contrato, duración del contrato, tipo de Jornada, flujos de la población activa, y retribuciones ${ }^{19}$.

Además anualmente el INE publica información sobre el empleo de las personas con discapacidad (Instituto Nacional de Estadítica, 2014) que integra datos provenientes de la EPA y datos administrativos registrados en la Base de Datos Estatal de Personas con Discapacidad del Instituto de Mayores y Servicios Sociales.

Y además la estadística de flujos de la EPA, personas que entran y que salen del empleo, permite conocer la situación de los empleados públicos en un trimestre dado según su relación con la actividad económica en el trimestre anterior: ocupados, parados, o inactivos.

\subsection{El Boletín Estadístico del Personal al Servicio de las Administraciones Públicas (BEPSAP)}

El Boletín Estadístico del Personal al Servicio de las Administraciones Públicas (BEPSAP) ${ }^{20}$ es una explotación del Registro Central de Personal ${ }^{21}$ y de fuentes administrativas de otras Administraciones Públicas. La estadística de función pública entre otros, excluye a los empleados de de las Comunidades Autónomas y de la Administración local que cuenten con un contrato temporal de menos de 6 meses y a un sector de empleados de la administración institucional.

Para todas las administraciones contiene información sobre el tipo de personal -funcionario o laboral-; el tipo de administración; la distribución provincial y de la administración exterior; y el género de los empleados públicos. Para la administración civil del Estado incluye además, datos sobre el número de efectivos por ministerio y organismo, la edad, el grupo profesional, y el nivel de destino de los empleados públicos.

Se publica semestralmente, en el primero toma como referencia a los que están empleados el 1 de enero y en el segundo a los que están empleados el 1 de julio. Desde 1990 el BEPSAP incluye a los egectivos que prestan servicio en la Administración Pública Estatal (Administración General del Estado, Fuerzas y Cuerpos de Seguridad del Estado, Fuerzas Armadas, Administración de Justicia y Entidades Públicas Empresariales

17 «Las personas ausentes de su trabajo por causa de enfermedad o accidente, vacaciones o licencia de maternidad, se consideran como personas con trabajo. Las ausentes por tener contratos fijos discontinuos, por ser trabajadores estacionales o por estar en espera para incorporarse a un nuevo empleo, se consideran sin empleo. Las ausentes por otros motivos distintos de los anteriores (por ejemplo: estar disfrutando una excedencia por nacimiento de un hijo, tener jornada de verano u horario flexible, estar desempeñando actividades de representación sindical, mal tiempo, paro parcial por razones técnicas o económicas, expediente de regulación, estar en huelga o conflicto laboral, haber recibido enseñanza o formación fuera del establecimiento, razones personales o responsabilidades familiares), se consideran asalariadas si el empleador les paga al menos el 50 por ciento de su sueldo o si van a reincorporarse a su empleo en los próximos tres meses. Los aprendices que hayan recibido una retribución en metálico o en especie y los estudiantes que hayan trabajado a cambio de una remuneración a tiempo completo o parcial se consideran como personas asalariadas y se clasifican como trabajando o sin trabajar sobre la misma base que las demás personas con trabajo por cuenta ajena. Los miembros activos de las fuerzas armadas figuran también entre la población asalariada» (INSTITUTO NACIONAL DE ESTADÍSTICA (INE), 2017, págs. 13-14).

18 La Clasificación de ocupaciones profesionales distingue diez grandes grupos: 1. Directores y gerentes; 2 . Técnicos y profesionales científicos e intelectuales; 3. Técnicos; profesionales de apoyo; 4 . Empleados contables, administrativos y otros empleados de oficina; 5 . Trabajadores de los servicios de restauración, personales, protección y vendedores; 6 . Trabajadores cualificados en el sector agrícola, ganadero, forestal y pesquero; 7. Artesanos y trabajadores cualificados de las industrias manufactureras y la construcción (excepto operadores de instalaciones y maquinaria); 8. Operadores de instalaciones y maquinaria, y montadores; 9. Ocupaciones elementales; 10. Ocupaciones militares.

19 Sobre las retribuciones percibidas por los empleados públicos contamos con varias fuentes, que incorporan distintas categorías: La Agencia Tributaria, Contabilidad Nacional, La Intervención general del Estado, y la Encuesta de Población Activa. Las estadísticas sobre retribuciones que publican la Agencia Tributaria, Contabilidad Nacional y la Intervención General del Estrado, provienen de la información de las entidades en las que trabajan los empleados públicos, mientras que la que ofrece la Encuesta de Población Activa, se obtiene mediante un variable derivada que parte de la posición del empleado y enlaza a los individuos de la muestra con los registros administrativos en lo que consta su información salarial individual.

20 En 1990 Boletín Estadístico del Registro Central de Personal, en 2001 Boletín del Personal al Servicio de las Administraciones Públicas, y desde 2002 Boletín Estadístico del Personal al Servicio de las Administraciones Públicas.

21 «En el Registro Central de Personal se encuentra inscrito, en virtud del artículo 1.1 de la Ley 30/1984, de 2 de agosto, de Medidas para la Reforma de la Función Pública, el siguiente personal: a) Personal de la Administración Civil del Estado y sus Organismos Autónomos. b) Personal civil al servicio de la Administración Militar y sus Organismos Autónomos. c) Personal funcionario de la Administración de la Seguridad Social. Asimismo se encuentra inscrito el personal laboral al servicio de la Administración de la Seguridad Social y el personal funcionario que, sin estar incluido en los apartados anteriores, ocupa puestos de trabajo de los Ministerios y sus Organismos Autónomos de acuerdo con lo que se determina en las respectivas relaciones de puestos de trabajo. También se encuentra inscrito el personal funcionario y laboral de las Agencias Estatales» (REGISTRO CENTRAL DE PERSONAL, julio 2018, pág. 10). 
y Organismos Públicos con régimen específico); las Administraciones de las Comunidades Autónomas; la Administración Local (Ayuntamientos, Diputaciones, Cabildos y Consejos Insulares) y las Universidades. Y no incluye a los altos cargos de las Administraciones Públicas, a los Cargos electos, al personal al servicio de los Órganos Constitucionales y Órganos equivalentes en las Comunidades Autónoma, al personal de Entidades Públicas Empresariales y Organismos Públicos con régimen específico de las Comunidades Autónomas y de la Administración Local equivalentes a los organismos públicos de la Administración General del Estado, al personal de empresas públicas, fundaciones, mutuas, consorcios y sector público no administrativo de las Administraciones Públicas, al personal en formación y prácticas, reserva, segunda actividad, o cualquier otra situación que no sea la de servicio activo de las Comunidades Autónomas y las Entidades Locales, y al Personal laboral con contratos de duración inferior a 6 meses de las Comunidades Autónoma, y al Personal del Centro Nacional de Inteligencia (Registro Central de Personal, julio 2018, págs. 4-5).

TABla 3. Comparación de las estadísticas de empleo público

\begin{tabular}{|c|c|c|}
\hline & Encuesta de Población Activa (EPA) & $\begin{array}{l}\text { Boletín estadístico del personal al servicio de } \\
\text { las Administraciones Públicas (BEPSAP) }\end{array}$ \\
\hline Ámbito temporal & Serie trimestral desde 1976. & Serie semestral desde 1990. \\
\hline Ámbito territorial & España. & España y Administración Exterior. \\
\hline Ámbito funcional & $\begin{array}{l}\text { Asalariados del sector público (sólo } \\
\text { actividad principal). }\end{array}$ & $\begin{array}{l}\text { Empleados públicos excepto temporales } \\
\text { de menos de seis meses y personal laboral } \\
\text { de entidades de derecho privado de las } \\
\text { Comunidades Autónomas. }\end{array}$ \\
\hline $\begin{array}{l}\text { Recogida de } \\
\text { información }\end{array}$ & $\begin{array}{l}\text { Muestra. } \\
\text { Cuestionario con encuestador. }\end{array}$ & $\begin{array}{l}\text { Registro administrativo individual (Registro } \\
\text { Central de Personal) y datos agregados } \\
\text { proporcionados por distintas administraciones. }\end{array}$ \\
\hline $\begin{array}{l}\text { Variables } \\
\text { principales }\end{array}$ & $\begin{array}{l}\text { - Género. } \\
\text { - Edad. } \\
\text { - Distribución territorial. } \\
\text { - Ocupación profesional. } \\
\text { - Tipo de administración. } \\
\text { - Tipo de contrato o relación laboral. } \\
\text { - Duración del contrato o relación laboral. } \\
\text { - Tipo de Jornada. } \\
\text { - Flujos de la población activa. } \\
\text { - Retribuciones. }\end{array}$ & $\begin{array}{l}\text { Para todas las administraciones: Tipo de } \\
\text { personal: Funcionario o laboral; Tipo de } \\
\text { administración; Distribución provincial y } \\
\text { genero. } \\
\text { Para la administración civil del estado incluye } \\
\text { además, efectivos por ministerio y organismo, } \\
\text { edad, grupo profesional, y nivel de destino. }\end{array}$ \\
\hline $\begin{array}{l}\text { Posibilidad de } \\
\text { comparación }\end{array}$ & $\begin{array}{l}\text { Permite comparaciones internacionales y } \\
\text { sectoriales. }\end{array}$ & $\begin{array}{l}\text { No permite comparaciones internacionales o } \\
\text { sectoriales. }\end{array}$ \\
\hline $\begin{array}{l}\text { Estructura } \\
\text { interna }\end{array}$ & No permite un análisis departamental. & $\begin{array}{l}\text { Permite un análisis de la estructura } \\
\text { departamental. }\end{array}$ \\
\hline
\end{tabular}

Fuente: Elaboración propia.

\section{LAS RETRIBUCIONES DE LOS EMPLEADOS PUBLICOS, REVISION DE FUENTES}

Al igual que para el empleo del sector público el Inventario de Operaciones Estadísticas agrupa bajo el epígrafe Administraciones públicas, estadísticas sobre las retribuciones del personal de las Administraciones Públicas. En este campo son especialmente relevantes las estadísticas del Mercado laboral y de las Cuentas económicas en las que se incorpora información detallada sobre las retribuciones y el gasto de personal del sector público (Tabla 4).

Sobre las retribuciones y los gastos de personal (Tabla 5) en el sector público contamos con tres fuentes principales: las estadísticas salariales del INE, la información que publica la Agencia Tributaria, y a partir de la Intervención General del Estado los datos de la Contabilidad Nacional. 
Las Encuestas de Estructura y de Coste Salarial utilizan las secciones de la Clasificación de Actividades Económicas y presentan agregada la sección Administración pública, Defensa y Seguridad social, que no incluye la educación y la sanidad que se detalla en otras secciones pero sin diferenciar el sector público y el privado. Ambas encuestas se refieren a los trabajadores por cuenta ajena incluidos en la Seguridad Social, lo que excluye a los trabajadores del sector público adscritos al Régimen de Clases Pasivas del Estado.

La estadística de retribuciones del sector público administrativo de la Administración General del Estado aporta información sobre la cuantía de cada uno de los conceptos ${ }^{22}$ retributivos del empleo público e información relevante sobre la masa salarial agrupada por tales conceptos.

Las estadísticas presupuestarias aportan mensualmente información agregada del gasto de personal que para la Administración General del Estado y para las Administraciones Locales se detalla según las categorías presupuestarias del capítulo de gastos de personal (altos cargos; personal eventual; funcionarios; laborales; otro personal; incentivos al rendimiento; y cuotas, prestaciones y gastos sociales a cargo empleador), mientras que en las estadísticas de los presupuestos de la Comunidades Autónomas los gastos de personal se presentan agrupados.

TABLA 4. LAS Retribuciones de los empleados públicos en el InVEntario de Operaciones Estadísticas

\begin{tabular}{|c|c|c|c|}
\hline Sector (tema) & $\begin{array}{l}\text { Subsector } \\
\text { (subtema) }\end{array}$ & $\begin{array}{l}\text { Operaciones más } \\
\text { relevante para las } \\
\text { retribuciones del sector } \\
\text { público }\end{array}$ & Otras operaciones \\
\hline \multirow[t]{2}{*}{$\begin{array}{l}\text { Administraciones } \\
\text { públicas y } \\
\text { asociaciones }\end{array}$} & $\begin{array}{l}\text { Personal de las } \\
\text { Administraciones } \\
\text { Públicas y sus } \\
\text { retribuciones. }\end{array}$ & $\begin{array}{l}\text { Estadística de } \\
\text { Retribuciones del Sector } \\
\text { Público Administrativo } \\
\text { de la AGE. }\end{array}$ & \\
\hline & $\begin{array}{l}\text { Presupuestarias y } \\
\text { fiscales. }\end{array}$ & & $\begin{array}{l}\text { - Estadística de Liquidación de los } \\
\text { Presupuestos del Estado y de sus } \\
\text { Organismos Públicos, Empresas y } \\
\text { Fundaciones. } \\
\text { - Liquidación de Presupuestos de las } \\
\text { Comunidades Autónomas. } \\
\text { - Liquidación de Presupuestos de las } \\
\text { Entidades Locales. } \\
\text { - Ejecución del Presupuesto del Estado. } \\
\text { - Avances de Liquidación de los } \\
\text { Presupuestos del Estado y de sus } \\
\text { Organismos Públicos. } \\
\text { - Ejecución Presupuestaria Mensual de las } \\
\text { Comunidades Autónomas. } \\
\text { - Ejecución Presupuestaria Trimestral de } \\
\text { las Entidades Locales. } \\
\text { - Presupuestos del Sector Público Local. } \\
\text { - Ejecución de los Presupuestos de } \\
\text { Organismos Públicos. } \\
\text { - Presupuestos de las Comunidades } \\
\text { Autónomas. } \\
\text { - Presupuestos de las Entidades Locales. }\end{array}$ \\
\hline $\begin{array}{l}\text { Mercado Laboral } \\
\text { y Salarios }\end{array}$ & Mercado laboral. & $\begin{array}{l}\text { Encuesta de Población } \\
\text { Activa. } \\
\text { Estadística del Mercado de } \\
\text { Trabajo y Pensiones en las } \\
\text { Fuentes Tributarias. }\end{array}$ & $\begin{array}{l}\text { Encuesta Cuatrienal de Estructura } \\
\text { Salarial. } \\
\text { Encuesta Cuatrienal de Coste Laboral } \\
\text { (ambas ocupados en la administración } \\
\text { pública, educación y sanidad, incluyendo } \\
\text { en estos últimos sectores el empleo } \\
\text { privado). }\end{array}$ \\
\hline
\end{tabular}

22 Grupo, destino, específico, trienios del personal funcionario y categorías del convenio único de personal laboral. 


\begin{tabular}{|c|c|c|c|}
\hline Sector (tema) & $\begin{array}{l}\text { Subsector } \\
\text { (subtema) }\end{array}$ & $\begin{array}{l}\text { Operaciones más } \\
\text { relevante para las } \\
\text { retribuciones del sector } \\
\text { público }\end{array}$ & Otras operaciones \\
\hline \multirow[t]{2}{*}{$\begin{array}{l}\text { Cuentas } \\
\text { económicas }\end{array}$} & $\begin{array}{l}\text { Contabilidad } \\
\text { Nacional. }\end{array}$ & $\begin{array}{l}\text { - Cuentas Trimestrales } \\
\text { no Financieras de los } \\
\text { Sectores Institucionales. } \\
\text { - Cuentas Anuales no } \\
\text { Financieras de los } \\
\text { Sectores Institucionales. }\end{array}$ & $\begin{array}{l}\text { - Contabilidad Nacional Anual de España: } \\
\text { Principales Agregados. } \\
\text { - Contabilidad Nacional Anual de España: } \\
\text { Agregados por Rama de Actividad. }\end{array}$ \\
\hline & $\begin{array}{l}\text { Cuentas de } \\
\text { sectores y } \\
\text { subsectores } \\
\text { institucionales. }\end{array}$ & $\begin{array}{l}\text { - Cuentas de las } \\
\text { Administraciones } \\
\text { Públicas. }\end{array}$ & $\begin{array}{l}\text { - Cuentas de las Empresas Públicas. } \\
\text { - Cuentas de las Administraciones Públicas } \\
\text { Territoriales. } \\
\text { - Cuentas Trimestrales de las } \\
\text { Administraciones Públicas. }\end{array}$ \\
\hline $\begin{array}{l}\text { Investigación } \\
\text { científica y } \\
\text { desarrollo } \\
\text { tecnológico }\end{array}$ & $\begin{array}{l}\text { Recursos } \\
\text { económicos, } \\
\text { personal y } \\
\text { actividades en } \\
\text { I+D. }\end{array}$ & & $\begin{array}{l}\text { - Estadística sobre Actividades en I+D en } \\
\text { el Sector Administración Pública. } \\
\text { - Estadística de Créditos Presupuestarios } \\
\text { (Iniciales y Finales) de I+D. }\end{array}$ \\
\hline $\begin{array}{l}\text { Educación y } \\
\text { Formación }\end{array}$ & $\begin{array}{l}\text { Personal y } \\
\text { aspectos } \\
\text { económicos de la } \\
\text { educación. }\end{array}$ & & $\begin{array}{l}\text { - Estadística de Gasto Público en } \\
\text { Educación. } \\
\text { - Estadística de Financiación y Gasto de } \\
\text { las Universidades Públicas Españolas. }\end{array}$ \\
\hline
\end{tabular}

Fuente: Elaboración propia.

Sobre las retribuciones de los empleados del sector público por su amplitud y desagregación las fuentes más relevantes son Contabilidad Nacional, La Agencia Tributaria y la estadística salarial de la EPA, que explican realidades diferentes y cuentan con una metodología también dispar (Tabla 5). La primera se refiere al gasto de personal de las instituciones públicas y las otras dos a las retribuciones percibidas por los empleados públicos.

\subsection{La estadística salarial de la Encuesta de Población Activa (EPA)}

La estadística salarial del INE presenta una variable derivada ${ }^{23}$ que conecta la muestra de la EPA con los registros de la Seguridad Social y de las Agencias Tributarias, de manera que la información sobre las retribuciones (Instituto Nacional de Estadística, 2013) del ámbito público o privado o de cualquiera de las categorías de la encuesta incorpora información objetiva de las retribuciones percibidas por los individuos de la muestra.

La encuesta presenta información agregada sobre todos los asalariados del sector público, que incluye a los trabajadores adscritos al Régimen de Clases Pasivas del Estado y al régimen de la Seguridad Social.

23 En este caso «en lugar de preguntar directamente a las personas de la muestra se ha preferido obtener la información mediante el uso de registros administrativos, pero dado que no existe ninguno que cumpla la definición establecida estrictamente, debido a tener diferentes metodologías y coberturas limitadas, la solución adoptada ha sido obtener la información de varios registros y, sobre la base de algunos datos adicionales, intentar encontrar los mejores estimadores de la variable objetivo. Por tanto, se trata de lo que se ha denominado en la literatura estadística una «variable derivada», dado que la necesidad de información no puede ser cubierta inmediatamente por referencia directa a la información disponible. Tal variable se obtiene mediante el encadenamiento de un conjunto de diferentes fuentes que proporcionan la información requerida, mediante combinación de datos. Siguiendo esta línea metodológica, se han utilizado para la estimación del salario, por un lado, los registros de las declaraciones anuales de retenciones e ingresos a cuenta del Impuesto de la Renta de las Personas Físicas (IRPF) de las administraciones tributarias y por otro, los registros del fichero general de afiliaciones y altas y el fichero de bases de cotización de la Tesorería General de la Seguridad Social. Para calcular la retribución bruta mensual se prorratean las pagas extraordinarias y los incentivos» (INSTITUTO NACIONAL DE ESTADÍSTICA (INE), 2017, págs. 7-8). 
GAPP. Nueva Época - N. ${ }^{\circ}$ 23, mayo-octubre 2020 - ISSN: 1989-8991 - DOI: 10.24965/gapp.i23.10686 - [Págs. 20-44]

Las fuentes de información sobre el empleo público en España: revisión, diagnóstico y propuestas de cambio

José María de Luxán Meléndez

La información "se refiere al salario mensual ${ }^{24}$ del empleo principal realizado por la persona en la semana de referencia de la encuesta, incluidas las retenciones a cuenta de impuestos sobre la renta del empleo y las cotizaciones obligatorias del trabajador a sistemas de seguridad social (salario mensual bruto)», lo que excluye el salario, la retenciones y las cotizaciones de los segundos empleos y en general las percepciones de renta distintas de las del empleo principal. La encuesta ofrece información sobre el salario medio para cada decil del Salario e información desagregada según el tipo de jornada. Permite comparaciones sectoriales e internacionales.

Tabla 5. Características de las fuentes estadísticas sobre las Retribuciones del empleo publico

\begin{tabular}{|c|c|c|}
\hline \multirow{3}{*}{$\begin{array}{l}\text { Por el } \\
\text { colectivo } \\
\text { sobre el que } \\
\text { se recoge } \\
\text { información }\end{array}$} & $\begin{array}{l}\text { El salario del empleo principal de } \\
\text { los asalariados del sector público. }\end{array}$ & $\begin{array}{l}\text { Encuesta de Población Activa (a partir de los registros } \\
\text { de la Seguridad Social y de las Agencias Tributarias). }\end{array}$ \\
\hline & $\begin{array}{l}\text { Remuneración de los asalariados } \\
\text { de las administraciones públicas. }\end{array}$ & $\begin{array}{l}\text { - Contabilidad Nacional/Intervención General del Estado } \\
\text { (incluye el gasto de todas las administraciones publicas } \\
\text { en retribuciones y costes laborales). } \\
\text { - Mercado de trabajo y pensiones en las fuentes } \\
\text { tributarias (retribuciones percibidas por una persona y } \\
\text { pagadas por una o varias entidades). }\end{array}$ \\
\hline & $\begin{array}{l}\text { Remuneración de los trabajadores } \\
\text { incluidos en la Seguridad Social. }\end{array}$ & - Encuesta de Estructura Salarial. \\
\hline \multirow[t]{3}{*}{$\begin{array}{l}\text { Por el } \\
\text { origen de la } \\
\text { información }\end{array}$} & $\begin{array}{l}\text { Información muestral y registro } \\
\text { administrativo. }\end{array}$ & $\begin{array}{l}\text { - Encuesta de Población Activa (registros de la Seguridad } \\
\text { Social y de las Agencias Tributarias). } \\
\text { - Encuesta de Estructura Salarial (registros de la } \\
\text { Seguridad Social y de las Agencias Tributarias). }\end{array}$ \\
\hline & Registro administrativo. & $\begin{array}{l}\text { - Mercado de trabajo y pensiones en las fuentes } \\
\text { tributarias (Agencia Tributaria). }\end{array}$ \\
\hline & Información administrativa. & - Contabilidad Nacional (Intervención general del Estado). \\
\hline \multirow{3}{*}{$\begin{array}{l}\text { Por el ámbito } \\
\text { geográfico }\end{array}$} & En todo el mundo. & - Contabilidad Nacional. \\
\hline & Residentes en España. & $\begin{array}{l}\text { - Encuesta de Población Activa. } \\
\text { - Encuesta de Estructura Salarial. }\end{array}$ \\
\hline & En parte de España. & - Mercado de trabajo y pensiones en las fuentes tributarias. \\
\hline \multirow{4}{*}{$\begin{array}{l}\text { Por la } \\
\text { referencia } \\
\text { temporal }\end{array}$} & Cuatrienal. & - Encuesta de Estructura Salarial. \\
\hline & Anuales. & $\begin{array}{l}\text { - Encuesta de Población Activa. } \\
\text { - Encuesta de Estructura Salarial. } \\
\text { - Contabilidad Nacional. } \\
\text { - Mercado de trabajo y pensiones en las fuentes } \\
\text { tributarias (todo el año). }\end{array}$ \\
\hline & Trimestrales & - Contabilidad Nacional. \\
\hline & Mensual. & - Contabilidad Nacional. \\
\hline $\begin{array}{l}\text { Por su empleo } \\
\text { internacional }\end{array}$ & EUROSTAT, OCDE, OIT. & $\begin{array}{l}\text { - Encuesta de Población Activa. } \\
\text { - Contabilidad Nacional. }\end{array}$ \\
\hline
\end{tabular}

Fuente: Elaboración propia.

24 «Las pagas extras y otros complementos anuales son considerados en la definición, dividiendo su cantidad por 12. También se incluyen los pagos por horas extras regulares, propinas y comisiones. Además, si es un empleo eventual de duración inferior a un mes, el salario será una estimación del que se obtendría para una duración de todo el mes por un empleo similar (la persona, al menos en principio, podría realizar otros empleos de esa índole en el mismo mes). Pero en cambio, si es un empleo a tiempo parcial no debe transformarse al equivalente a tiempo completo (se trata del empleo principal y por tanto es el que proporciona los ingresos más significativos)» (INSTITUTO NACIONAL DE ESTADÍSTICA (INE), 2017, pág. 7). 


\subsection{Contabilidad Nacional}

Conforme al sistema europeo de cuentas nacionales y regionales ${ }^{25}$, Contabilidad Nacional, a partir de la Intervención General del Estado, publica periódicamente datos agregados sobre la remuneración de los asalariados que incluye sueldos y salarios percibidos en efectivo o en especie, y las cotizaciones sociales efectivas o imputadas a cargo de los empleadores del sector administraciones públicas que incluye a la administración central, las administraciones autonómicas, las administraciones locales y los fondos de la seguridad social. Esta información permite comparaciones homogéneas de ámbito sectorial $^{26}$ e internacional ${ }^{27}$.

\subsection{La estadística de la Agencia Tributaria}

La Agencia Tributaria ${ }^{28}$ publica desde 1999 la estadística "Mercado de trabajo y Pensiones en las fuentes tributarias" en la que desde 2006 se desglosa el sector de las administraciones públicas, primero unido a instituciones privadas sin fines de lucro y dese 2007, de forma separada. La Agencia aporta datos de los salarios por tramos de retribución, género, y tipo de entidad ${ }^{29}$ según el número de empleados. Permite comparaciones sectoriales y no internacionales.

TABla 6. Comparación de las estadísticas de las Retribuciones del empleo público

\begin{tabular}{|c|c|c|c|}
\hline & $\begin{array}{c}\text { Encuesta Salarial en } \\
\text { la EPA }\end{array}$ & Agencia Tributaria & Contabilidad Nacional \\
\hline Ámbito temporal & Serie anual desde 2006. & $\begin{array}{l}\text { Serie anual desde } 1999, \\
\text { con datos administraciones } \\
\text { públicas desde } 2006 \text {. }\end{array}$ & $\begin{array}{l}\text { Serie anual, trimestral y mensual } \\
\text { desde } 1995 .\end{array}$ \\
\hline Ámbito territorial & España. & $\begin{array}{l}\text { Parte de España (no incluye } \\
\text { agencias tributaria forales). }\end{array}$ & $\begin{array}{l}\text { Agregados de las cuentas de las } \\
\text { Administraciones Públicas (AAPP). }\end{array}$ \\
\hline $\begin{array}{l}\text { Ámbito } \\
\text { conceptual }\end{array}$ & $\begin{array}{l}\text { Retribuciones percibidas } \\
\text { por los asalariados del } \\
\text { sector público (sólo } \\
\text { actividad principal). }\end{array}$ & $\begin{array}{l}\text { Retribuciones y retenciones } \\
\text { perceptores de renta. }\end{array}$ & $\begin{array}{l}\text { Gasto de personal de las } \\
\text { instituciones del sector público. }\end{array}$ \\
\hline $\begin{array}{l}\text { Recogida de } \\
\text { información }\end{array}$ & $\begin{array}{l}\text { Muestra + registro } \\
\text { agencias tributarias y } \\
\text { Seguridad Social. }\end{array}$ & Registro Agencia Tributaria. & $\begin{array}{l}\text { Información Administrativa } \\
\text { (Intervención General del Estado). }\end{array}$ \\
\hline $\begin{array}{l}\text { Variables } \\
\text { principales }\end{array}$ & $\begin{array}{l}\text { - Salario medio. } \\
\text { - Tipo de jornada. } \\
\text { - Decil del salario. }\end{array}$ & $\begin{array}{l}\text { - Tramo de retribución. } \\
\text { - Genero. } \\
\text { - Número de empleados de } \\
\text { la entidad pagadora. } \\
\text { - Comunidad Autónoma de } \\
\text { residencia. }\end{array}$ & $\begin{array}{l}\text { - Sueldos y salarios en efectivo y } \\
\text { en especie. } \\
\text { - Cotizaciones sociales a cargo de } \\
\text { los empleadores. } \\
\text { - Admón. Central. } \\
\text { - Admón. autonómica. } \\
\text { - Admón. Local. } \\
\text { - Seguridad Social. }\end{array}$ \\
\hline
\end{tabular}

25 Reglamento (UE) núm. 549/2013 del Parlamento Europeo y del Consejo, de 21 de mayo de 2013, relativo al sistema europeo de cuentas nacionales y regionales.

${ }_{26}$ https://www.ine.es/dyngs/INEbase/es/operacion.htm?c=Estadistica_C\&cid=1254736165305\&menu=resultados\&i $d p=1254735576581$

27 https://ec.europa.eu/eurostat/web/government-finance-statistics/data/database.

28 https://www.agenciatributaria.es/AEAT.internet/datosabiertos/catalogo/hacienda/Mercado_de_Trabajo_y_Pensiones_en_las_ Fuentes_Tributarias.shtml?mobileView=true.

${ }_{29}$ En 2017 ofrece datos de 13.567 entidades agrupadas por el número de empleados. 


\begin{tabular}{l|l|l|l}
\hline \multicolumn{2}{c}{} & \multicolumn{1}{c}{$\begin{array}{c}\text { Encuesta Salarial en } \\
\text { la EPA }\end{array}$} & \multicolumn{1}{c}{ Agencia Tributaria } \\
\hline Comparación & $\begin{array}{l}\text { Permite comparaciones } \\
\text { internacionales y } \\
\text { sectoriales. }\end{array}$ & $\begin{array}{l}\text { Permite comparaciones } \\
\text { sectoriales y no } \\
\text { internacionales. }\end{array}$ & $\begin{array}{l}\text { Permite comparaciones } \\
\text { internacionales y sectoriales. }\end{array}$ \\
\hline $\begin{array}{l}\text { Estructura } \\
\text { interna }\end{array}$ & $\begin{array}{l}\text { No permite un análisis } \\
\text { departamental. }\end{array}$ & $\begin{array}{l}\text { Permite un análisis por } \\
\text { tamaño de la entidad. }\end{array}$ & $\begin{array}{l}\text { No permite un análisis de la } \\
\text { estructura departamental. }\end{array}$ \\
\hline
\end{tabular}

Fuente: Elaboración propia.

\section{COMPARACIÓN DE FUENTES}

Para analizar que la imagen que se construye sobre las retribuciones o sobre el tamaño y características del empleo público varía en función de la estadística a la que se acuda se detallan cinco casos relevantes que ayudan a valorar la distorsión que pueda haber entre las distintas fuentes y la posibilidad de realizar comparaciones sectoriales o internacionales. Para ello se presentan nueve figuras sobre el número de empleados, el empleo femenino, y el peso del empleo de las Comunidades Autónomas, la temporalidad en el empleo público, y el gasto de personal.

En algunas figuras los datos se refieren a un parámetro análogo (Número de empleados; Empleo femenino; Empleo de la Administración de las Comunidades Autónomas; Gasto de personal) que provienen de distintas fuentes. Y en otras se persigue señalar la posibilidad de comparaciones entre los sectores público y privado (Número de asalariados; Temporalidad).

El interés de analizar el número de empleados públicos (Figura 1) deriva de su importancia para describir uno de los factores centrales de la expansión del estado que adquiere mayor relevancia si se compara con la evolución del sector privado (Figura 2).

El incremento del empleo público, uno de los grandes cambios del proceso de modernización socioeconómica de la democracia, debe un $80 \%$ de su crecimiento al aumento del empleo femenino (Figura 4) por lo que es relevante comprobar si las diferencias metodológicas de la EPA y del Boletín estadístico del personal al servicio de la administración pública (Figura 3) implican algún tipo de sesgo.

Entre las reformas que impulsó la Constitución, el desarrollo de las Comunidades Autónomas comporta una profunda transformación de la organización del Estado por lo que es muy relevante valorar como se expresa en las distintas estadísticas (Figuras 5 y 6 ).

El incremento de la temporalidad es una de las novedades de la política de empleo público y para medir su alcance sólo se cuenta con información de la EPA que puede compararse con la evolución del empleo privado (Figura 7).

Un quinto tema inmediatamente vinculado al número de empleados es el gasto de personal. Aquí es relevante comprobar si las diferencias metodológicas de contabilidad Nacional (CN) y la Agencia Tributaria (Figura 8) implican algún tipo de sesgo. Y además para analizar el coste de las retribuciones es útil tener en cuenta su evolución en relación con el Producto Interior Bruto tanto en España como en la Unión Europea (Figura 9).

\subsection{El número de empleados}

En la Figura 1 se representa la evolución entre 2000 y 2018 del número de empleados del ámbito público según las distintas fuentes estadísticas: Agencia Tributaria, EPA, Contabilidad Nacional -síntesis-, Boletín estadístico del personal al servicio de la administración pública -función pública-, y la Seguridad Social.

Como era de esperar dado que tienen características diferentes todas las estadísticas tienen resultados dispares. La Agencia tributaria, la EPA y la estadística de síntesis de Contabilidad Nacional se refieren a la totalidad de los asalariados del sector público, mientras que el BEPSAP -función pública- y la Seguridad Social cuentan sólo con una parte de los empleados públicos.

Para ver la dificultad de la definición del alcance de las operaciones estadísticas sobre el empleo público se pueden señalar un ejemplo: En la EPA alrededor de un 0,35\% de los asalariados públicos cuando se les pregunta por la administración en la que trabajan no la identifican y la EPA presenta los datos como otro tipo o no sabe. 
Figura 1. Número de Empleados PÚblicos en EsPAÑa (2000-2018)

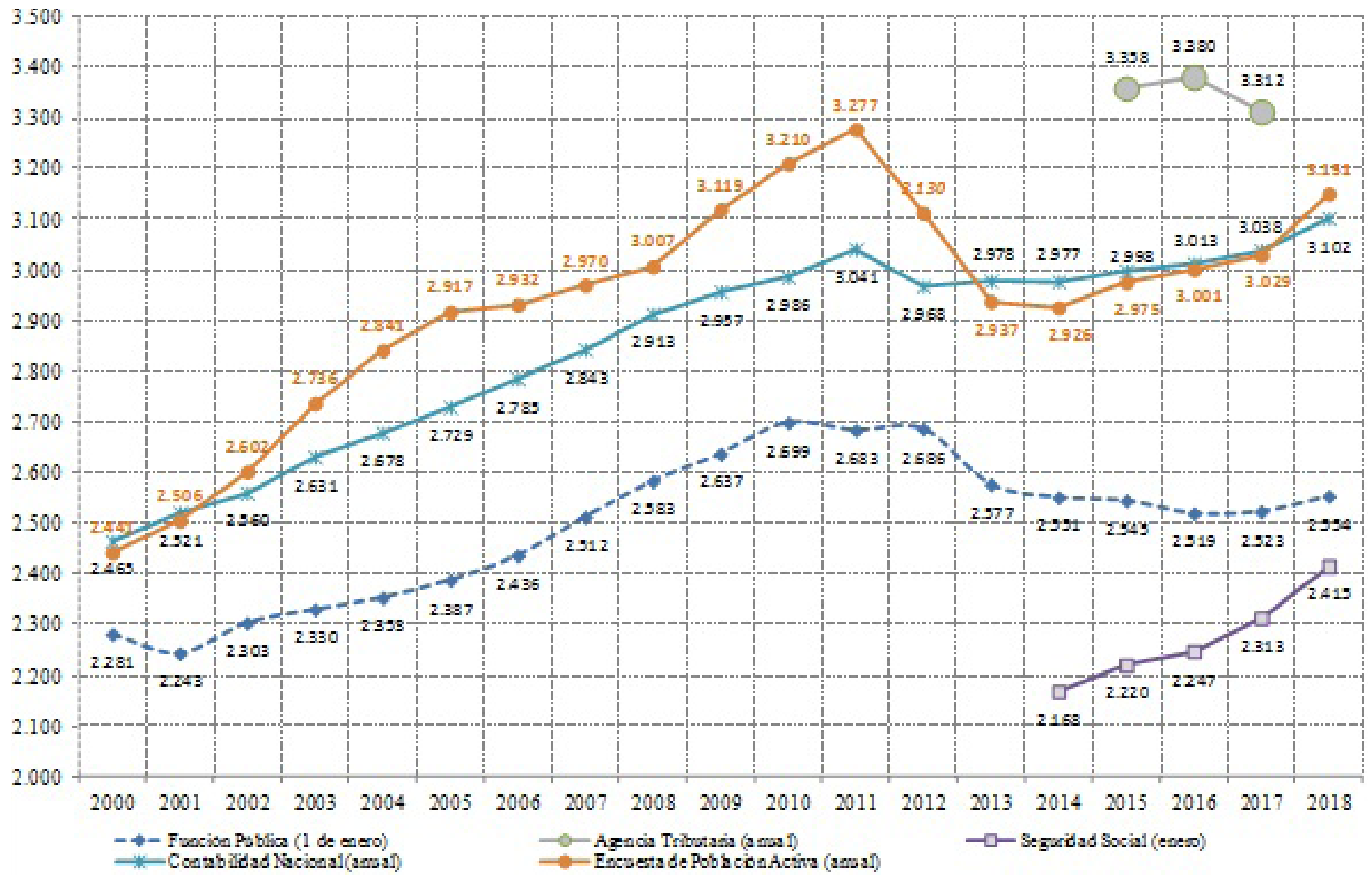

Fuente: Elaboración propia. Varias fuentes, unidades en miles.

En todos los años, los datos de la EPA son sensiblemente superiores a los de función pública. En promedio anual la diferencia es de 436.000 empleados, lo que supone un $17,4 \%$ adicional en la EPA sobre la estadística del BEPSAP.

Igualmente, hasta 2012, los datos de la EPA son superiores a los de Contabilidad Nacional, mientras que están muy próximos desde 2013. En promedio anual la diferencia es de 79.150 empleados, lo que supone un 2,6\% adicional en la EPA sobre la estadística de síntesis de Contabilidad Nacional, distancia que desde 2013 , en media anual, se ha reducido a un $-0,5 \%$.

Los datos de Contabilidad Nacional, en todos los años, son superiores a los de función pública (BEPSAP). En promedio anual la diferencia es de 372.328 empleados, lo que supone un $12,7 \%$ adicional en Contabilidad Nacional sobre la estadística función pública (BEPSAP), distancia que desde 2013, en media anual, ha aumentado hasta un $15,7 \%$.

La EPA y la estadística de función pública (BEPSAP) evolucionan de forma análoga, guardan una correlación ${ }^{30}$ positiva. E igualmente la EPA y la síntesis de Contabilidad Nacional también guardan una correlación ${ }^{31}$ positiva, y sus diferencias metodológicas, justifican que en algunos años difieran mucho. $Y$ aunque las diferencias cuantitativas sean importantes, la síntesis de Contabilidad Nacional, también un guarda correlación ${ }^{32}$ positiva con los datos publicados por función pública (BEPSAP).

$30 R^{2}$ 0,84 entre la estadística de función pública (BESAP) y EPA anual para el periodo 2000 a 2018 .

$31 R^{2} 0,82$ entre Contabilidad nacional y EPA anual para el periodo 2000 a 2018.

$32 R^{2} 0,80$ entre Contabilidad nacional anual y función pública (BEPSAP) para el periodo 2000 a 2018. 
Figura 2. Número de ASALARIAdos de LOS SECTORES PÚblico Y PRIVAdo (1976-2019) en la Encuesta de Población Activa

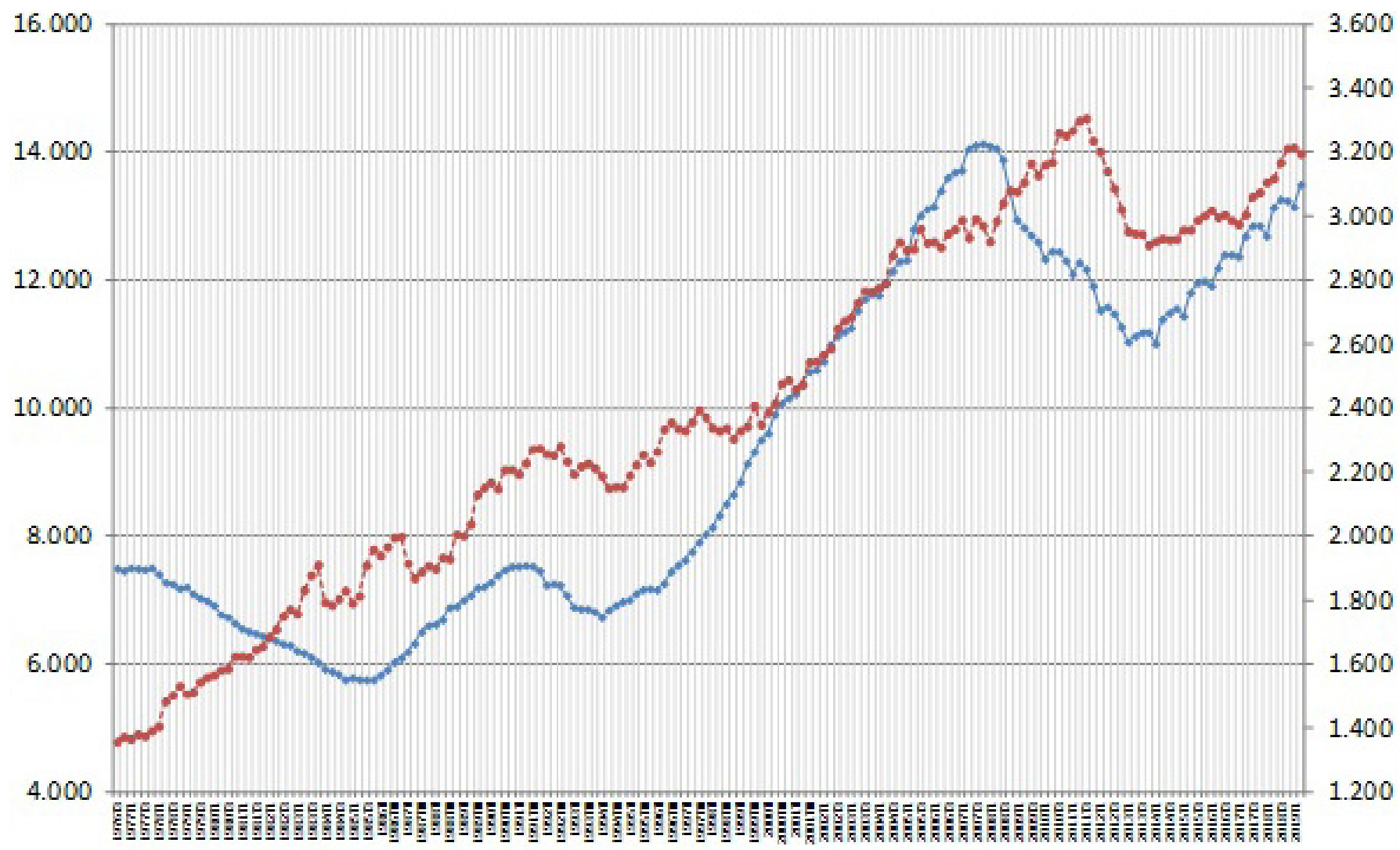

$\rightarrow$ asalariados sector privado (eje izquier do) _ _... asalariados sector público (eje derecho)

Fuente: Elaboración propia, unidades en miles, EPA trimestral, último dato 2T 2019.

La serie temporal que proporciona la EPA es la de mayor amplitud, y además permite la posibilidad de realizar comparaciones internacionales o sectoriales de ámbito nacional.

Si se opta por los datos de la EPA (Figura 2) puede observarse la evolución trimestral desde 1976. Un periodo de transformación económica y política en el que el número total de empleados públicos según la EPA ha pasado de 1.358 .100 a 3.194 .500 , lo que supone un incremento de un $235 \%$, mientras que en el ámbito privado, los asalariados han pasado de 7.498 .100 a 13.493 .800 , lo que supone un incremento igualmente muy importante, un $180 \%$, pero menor que el público.

Desde 1976 la continuidad de la orientación expansiva de la política del empleo público es coherente con los incrementos de la población y del PIB (Luxán Meléndez, 2016). Y vinculado con ambas variables, la expansión del empleo público guarda una correlación positiva $\left(R^{2} 0,81\right)$ con el incremento del número de asalariados.

Desde 1976 la variación media respecto al trimestre inmediatamente anterior ha sido de un 0,51\%. Este incremento se redujo entre el cuarto trimestre de 2011 y el cuarto de 2013, un periodo que acumuló una disminución de 397.200 Empleos netos, con un ritmo medio de disminución de -1,31\% intertrimestral, y aunque un ajuste en el empleo público no sea la primera vez que se produce, este ha sido el que comprende un periodo de disminución continuada de mayor duración e intensidad: 9 trimestres seguidos y una disminución del $12 \%$.

\subsection{El empleo femenino}

En la Figura 3 se representa la evolución entre 2007 y 2018 del peso del empleo público femenino según las dos fuentes disponibles: EPA, y Función pública (BEPSAP). 
GAPP. Nueva Época - N. ${ }^{\circ}$ 23, mayo-octubre 2020 - ISSN: 1989-8991 - DOI: 10.24965/gapp.i23.10686 - [Págs. 20-44]

Las fuentes de información sobre el empleo público en España: revisión, diagnóstico y propuestas de cambio

José María de Luxán Meléndez

En ambas estadísticas el empleo femenino supera siempre el $50 \%$ del total del empleo, y las dos evolucionan de forma análoga ${ }^{33}$, Pero en los años centrales de la crisis (2010-2013) si se considera la EPA el empleo femenino tuvo mucho mayor peso que el que tendría si se tiene en cuenta el BEPSAP. Las diferencias entre ambas estadísticas derivan del mayor peso femenino en el colectivo que no recoge el BEPSAP.

El periodo 2007-2018 es una etapa de crecimiento y disminución acelerada del peso del empleo femenino (Figura 3). Para la EPA hasta 2011 hubo una variación muy importante del empleo público femenino, que disminuyo en 2013-2014, para volver a incrementarse hasta 2019. Para el Boletín estadístico del personal al servicio de la administración pública la tasa de empleo femenino evoluciono de forma mucho más suave.

Figura 3. Proporción de empleo femenino en el Ámbito público (2007-2018)

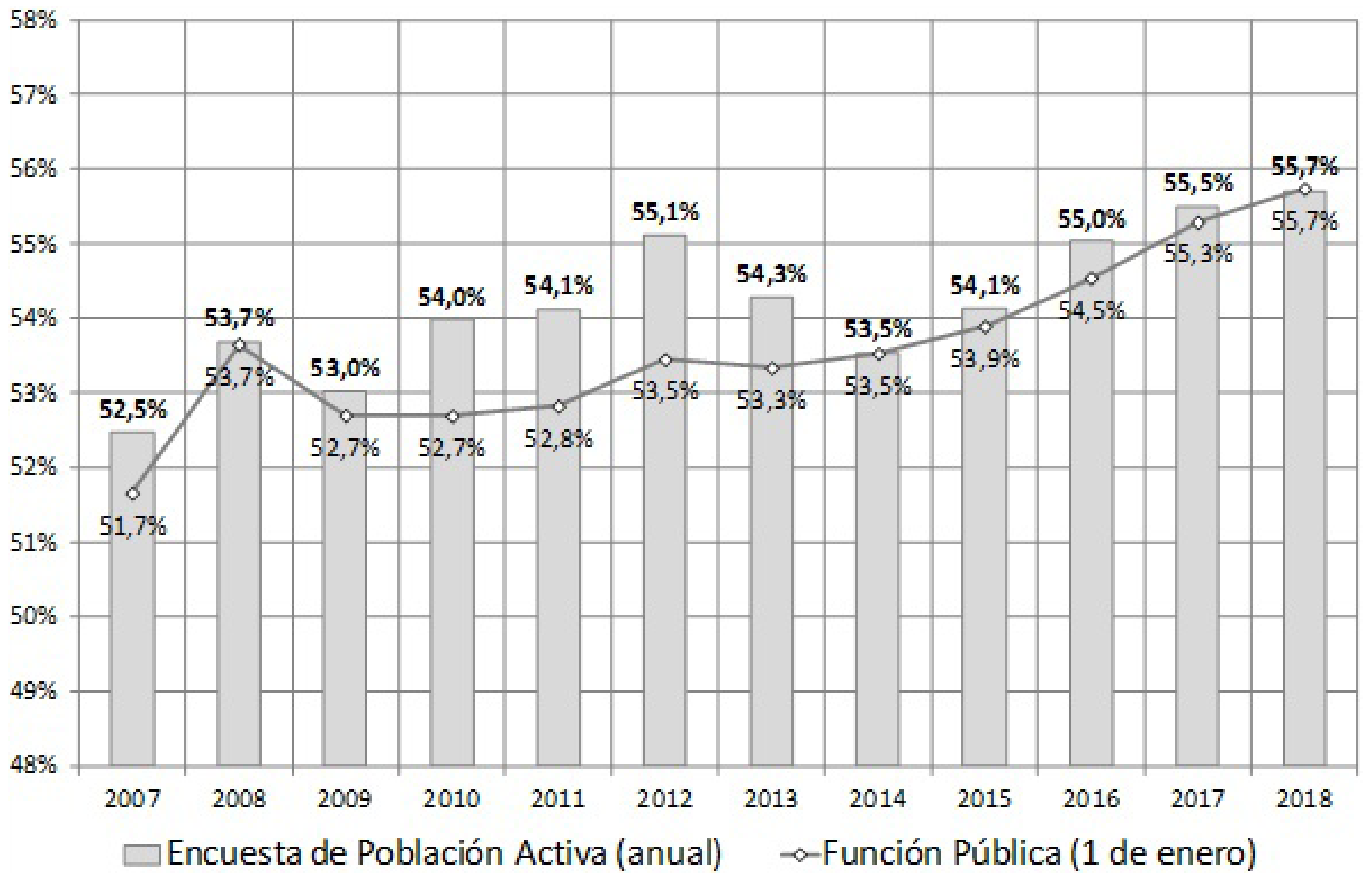

Fuente: Elaboración propia: EPA (anual) y BEPSAP -función pública- (1 de enero).

Dado que la serie temporal que proporciona la EPA es la de mayor amplitud, se puede acreditar que el incremento del empleo público, uno de los grandes cambios del proceso de modernización socioeconómica de la democracia, debe un $80 \%$ de su crecimiento al aumento del empleo femenino (Luxán Meléndez, 2018). Si se observa la Figura 4 se puede comprobar que el incremento del total del empleo público es paralelo al del empleo público femenino, que guardan una altísima correlación $\left(R^{2} 0,99\right)$ mientras que la correlación entre la evolución del empleo público masculino y el femenino es pequeña $\left(R^{2} 0,69\right)$.

33 Guardan una correlación positiva $\left(R^{2} 0,74\right)$. 
GAPP. Nueva Época - N. ${ }^{\circ}$ 23, mayo-octubre 2020 - ISSN: 1989-8991 - DOI: 10.24965/gapp.i23.10686 - [Págs. 20-44]

Las fuentes de información sobre el empleo público en España: revisión, diagnóstico y propuestas de cambio José María de Luxán Meléndez

Figura 4. El empleo público en España (1976-2019) en la Encuesta de Población Activa

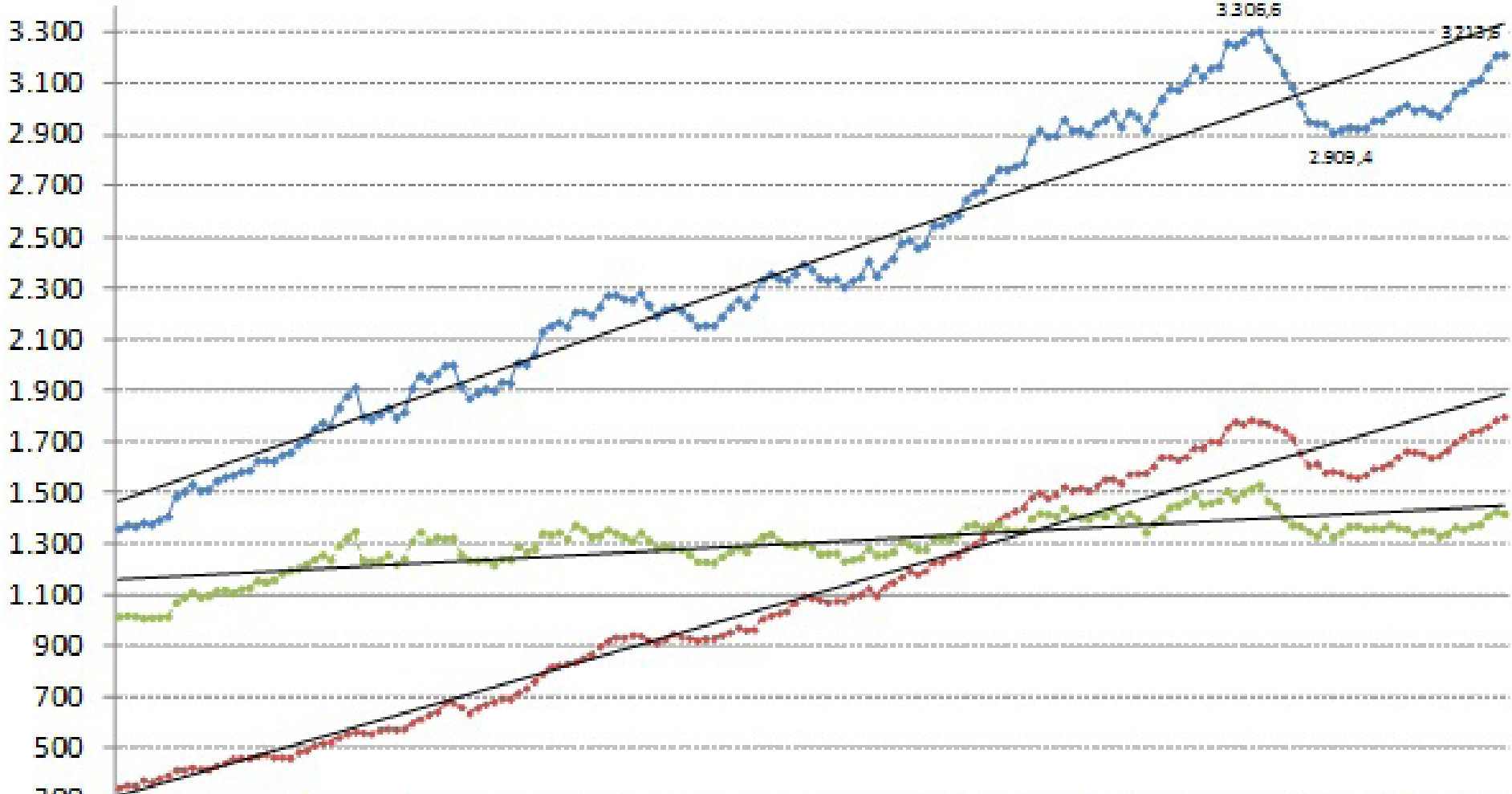

300

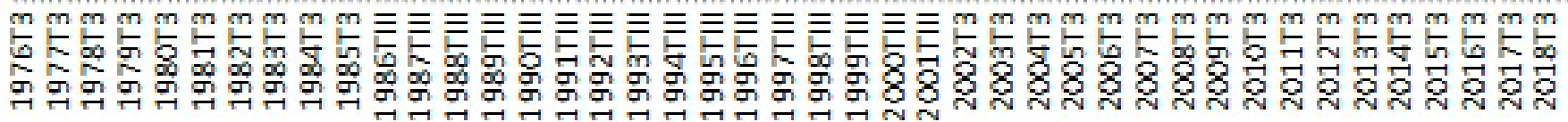

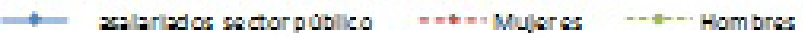

Fuente: Elaboración propia, número de asalariados del Sector Público, unidades en miles, INE, EPA trimestral, último dato 1T 2019.

\subsection{Comunidades Autónomas}

En la Figura 5 se representa la evolución entre 2007 y 2018 del número de empleados de las Comunidades Autónomas según las fuentes disponibles: Encuesta de Población Activa, y Boletín estadístico del personal al servicio de la administración pública -función pública-.

Dada la metodología de ambas estadísticas la distorsión entre ambas fuentes es primero cuantitativa, la EPA de media recoge 236.550 empelados adicionales, lo que representa el $52 \%$ de la diferencia entre ambas estadísticas. $Y$ en segundo término también es cualitativa, ambas variables no tienen una correlación alta $\left(R^{2} 0.67\right)$.

Para el BEPSAP, como no recoge un importante número de empleados de las Comunidades Autónomas, la variación interanual es relativamente pequeña, y la estadística ofrece una imagen de estabilidad. Mientras que para la EPA la volatilidad es más acusada: hay un incremento hasta 2011, luego con mayor rapidez una disminución hasta 2013, que se frena en 2014, para volver a incrementarse hasta 2018.

Si se observa la Figura 6 en ambas estadísticas las Comunidades Autónomas superan siempre el $50 \%$ del total del empleo público, pero evolucionan de forma dispar, no guardan correlación $\left(R^{2} 0,36\right)$. De acuerdo con la EPA el peso de las Comunidades Autónomas en el sector público español pasó de 2007 a 2012 de un $52,8 \%$ a un 55,9\%, para disminuir hasta $54,5 \%$ en 2014 y volver a incrementarse a un $56,8 \%$ en 2018. 
Figura 5. El empleo público en la Administración de las Comunidades Autónomas (2007-2018) COMPARACIÓN DE FUENTES

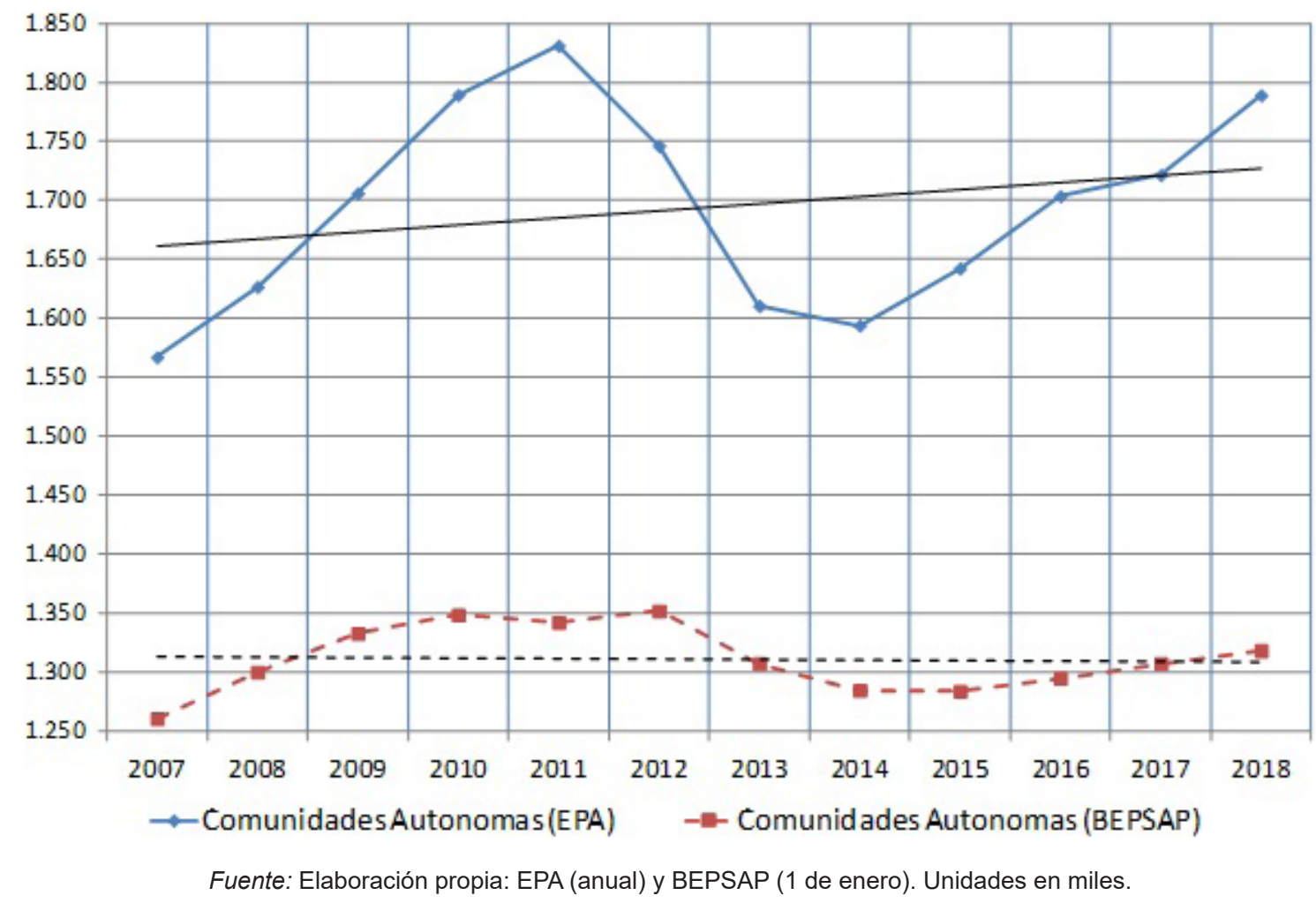

Figura 6. Proporción del empleo público de la Administración de las Comunidades Autónomas SOBRE EL TOTAL DEL ÁMBITO PÚBLICO (2007-2018) COMPARACIÓN DE FUENTES

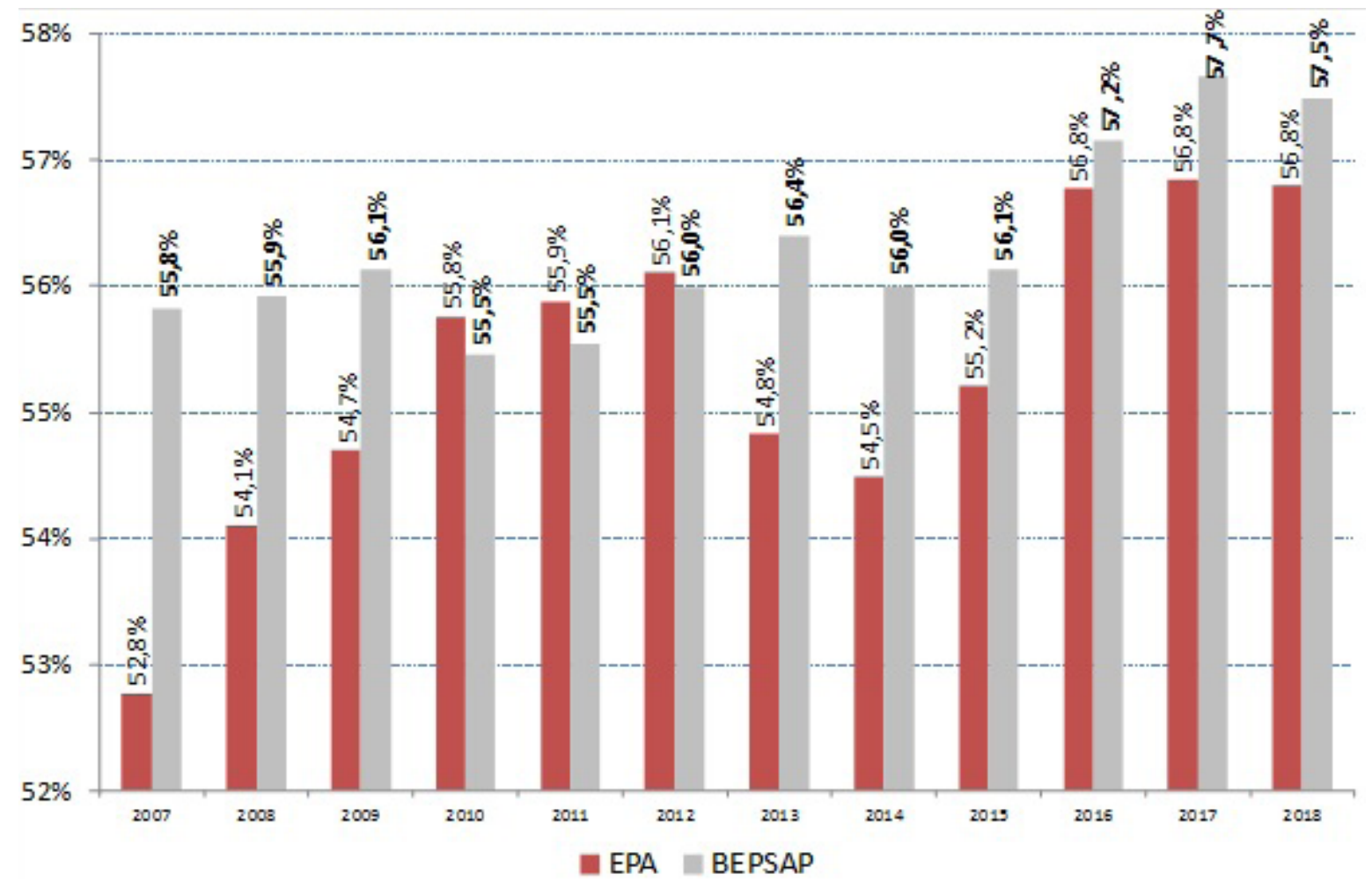

Fuente: Elaboración propia: EPA (anual) y BEPSAP (1 de enero). 


\subsection{Temporalidad}

Para medir el peso de la temporalidad en el empleo público, sólo contamos con la EPA. Entre 2002 y 2018, en la evolución de la temporalidad de los sectores públicos y privado (Figura 7 ) se pueden señalar cuatro etapas:

a) Inicialmente, hasta 2005 , en el sector público la temporalidad del empleo es mucho menor que en el sector privado. Y la diferencia entre ambos permanece estable.

b) Entre otros factores, como consecuencia del cambio de orientación de la política laboral, en el trienio 2006-2008, en el sector privado se redujo muy rápidamente el porcentaje de contratos temporales, hasta igualarse a los del sector público que, a diferencia del privado, se mantendrá estable.

c) Durante el primer bienio de la crisis, 2009 y 2010, en un contexto de masivo incremento del paro, en ambos sectores la tasa de trabajo temporal permanece, de media trimestral, en un $25 \%$.

d) A partir de 2011, en el ámbito público, en un contexto de reducción del empleo público, se observa una disminución del peso relativo de los contratos temporales, que, con un $19 \%$, alcanzará su cota más baja en el primer trimestre de 2013, mientras que en el sector privado, en términos porcentuales, la disminución es más suave.

e) Desde 2013, el peso de los contratos temporales se incrementara progresivamente en los sectores público y privado. El incremento es especialmente intenso en el sector público que llega hasta un $26,8 \%$. y por primera vez, en el primer trimestre de 2019 , se sitúa por encima de la temporalidad del ámbito privado. En el sector público de manera constante desde el primer trimestre de 2013 se ha incrementado la temporalidad, que ha pasado de un $19 \%$ a un $26.8 \%$ en el primer trimestre de 2019 , con un incremento neto en cinco años de 303,100 empleos temporales adicionales que absorbe la totalidad del descenso de los empleos de duración indefinida, que en el mismo periodo se redujeron en 41.200 empleos netos, lo que se tradujo en un saldo de 261,900 empleos adicionales en el ámbito público.

\section{FiguRA 7. PROPORCIÓN DE ASALARIADOS CON CONTRATO TEMPORAL 2002-2019 ELABORACIÓN PROPIA: EPA (TRIMESTRAL) ÚLTIMO DATO 1T 2019}

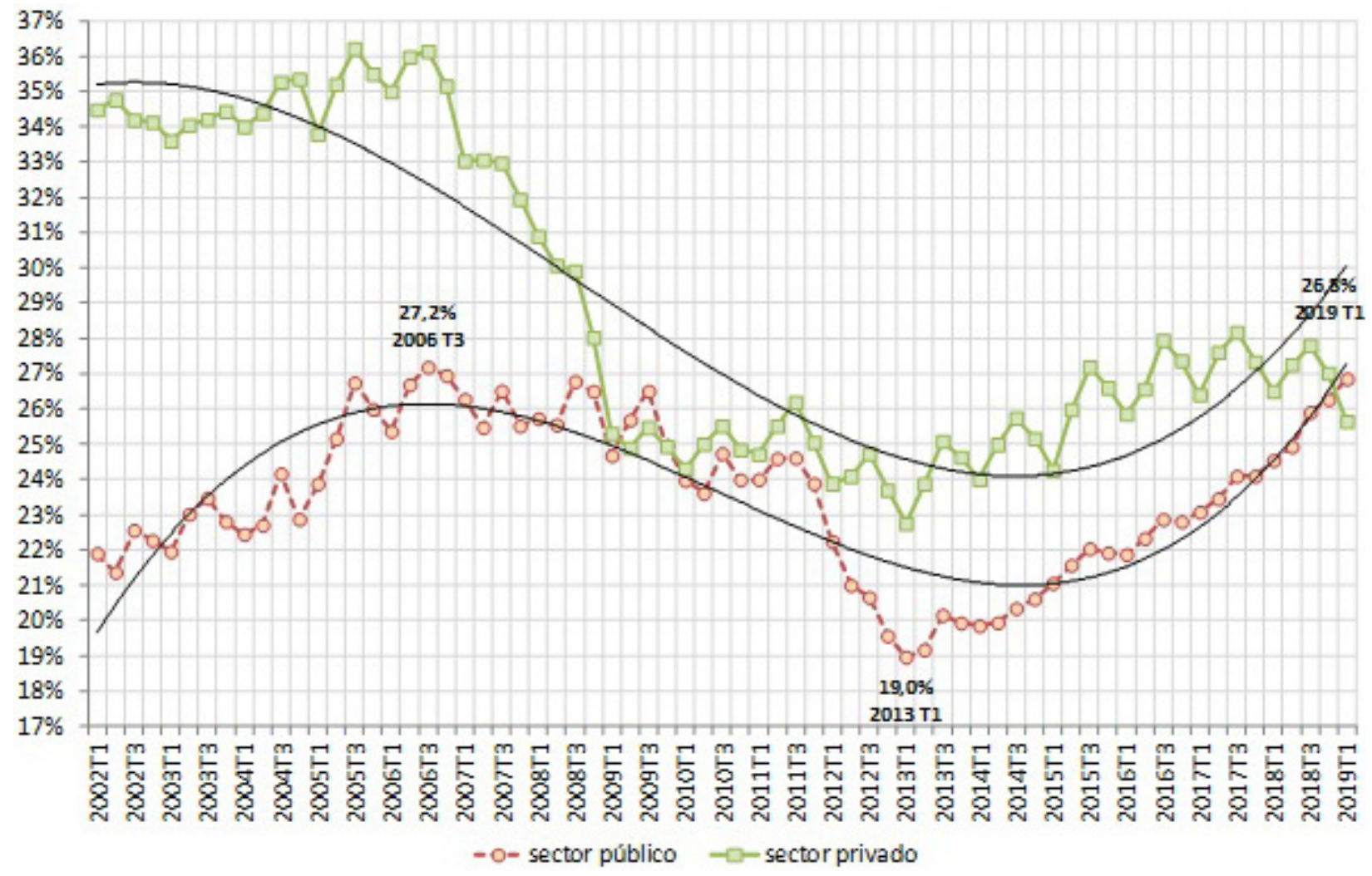

Fuente: Elaboración propia: EPA (trimestral) último dato 1T 2019. 
Sólo si se acude la EPA los datos contradicen la presunción de una mayor inamovilidad en el sector público. Frente a la idea de que el empleo público es esencialmente indefinido, o al menos que es más inamovible que el empleo del sector privado, llama la atención el alto grado de elasticidad del empleo público a través de los contratos temporales, que desde 2009, tiene primero un brusco descenso y luego un rápido crecimiento.

\subsection{El gasto de personal}

Para conocer la cuantía del gasto de personal contamos con la información de Contabilidad Nacional y de la Agencia Tributaria. Como era de esperar ambas estadísticas (Figura 8) son homogéneas y tienen una correlación positiva muy alta (R2 0.97). Ambas se refieren a la totalidad del ejercicio y recogen las remuneraciones percibidas por todos los que han trabajado en el sector público en algún momento del año. La diferencia cuantitativa se debe a que la estadística tributaria no recoge a las agencias tributarias de Navarra y del País Vasco.

FigURA 8. GASTO EN SUELDOS Y SALARIOS EN LAS ADMINISTRACIONES PÚBLICAS 2007-2017

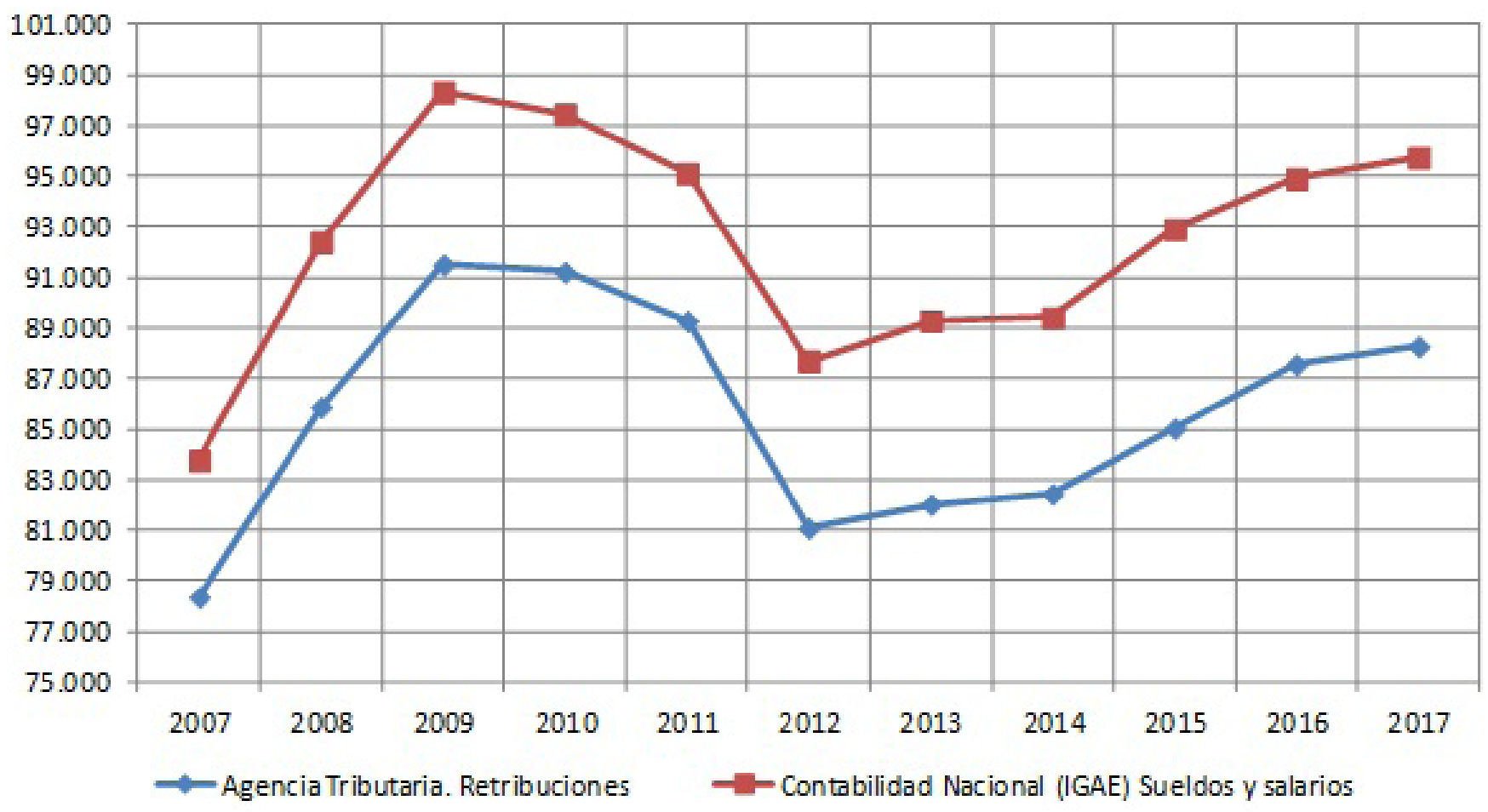

Fuente: Elaboración propia: Agencia Tributaria y Contabilidad Nacional (IGAE). Unidades en millones de euros.

En la Figura 9 se muestra un ejemplo sobre la posibilidad de realizar comparaciones internacionales. Se presenta el gasto de personal en el sector público en proporción al PIB en España y en la Unión Europea (28 países). Hasta 2007 el gasto salarial en el sector público español era inferior al de los países europeos, mientras que desde 2008 ha estado siempre por encima.

La evolución de las retribuciones del sector público varía entre los países europeos. Y hay que recordar que en el número de empleados también «...existen grandes diferencias entre los países de la OCDE, en lo referido al tamaño de las plantillas de la Administración. Por ejemplo, en 2008 las administraciones de Noruega y Dinamarca emplean cerca del $30 \%$ de la población activa... Sin embargo, los datos de empleo deben ser interpretados con precaución y junto con datos sobre los costes de producción y la externalización puesto que, solos, no son un indicador fiable del tamaño de la Administración» (OCDE, 2011).

Entre 2001 y 2007, antes de la crisis, los países de la Unión Europea disminuyeron ligeramente el coste de las retribuciones de los empleados públicos, pasando de un $10,2 \%$ a un $10,1 \%$ del PIB, mientras que en España se mantuvo estable, con un porcentaje ligeramente inferior, de media un 9,8\%. 
Al inicio de la crisis, entre 2008 y 2009, los países de la Unión Europea incrementaron notablemente el gasto de personal hasta llegar a un $11 \%$, por su parte España superó a los países de la Unión y pasó de un $9,9 \%$ a un $11,6 \%$, con un incremento que duplico al Europeo.

Desde 2010 la evolución del peso de las remuneraciones del sector público en Europa y España, con la notable excepción de 2012, mantienen una curva de descenso paralelo, hasta situarse en un 9,9\% en los países de la Unión Europea, y un 10,5\% en España.

Figura 9. Gasto de personal en el sector publico en \% SOBRe El PIB

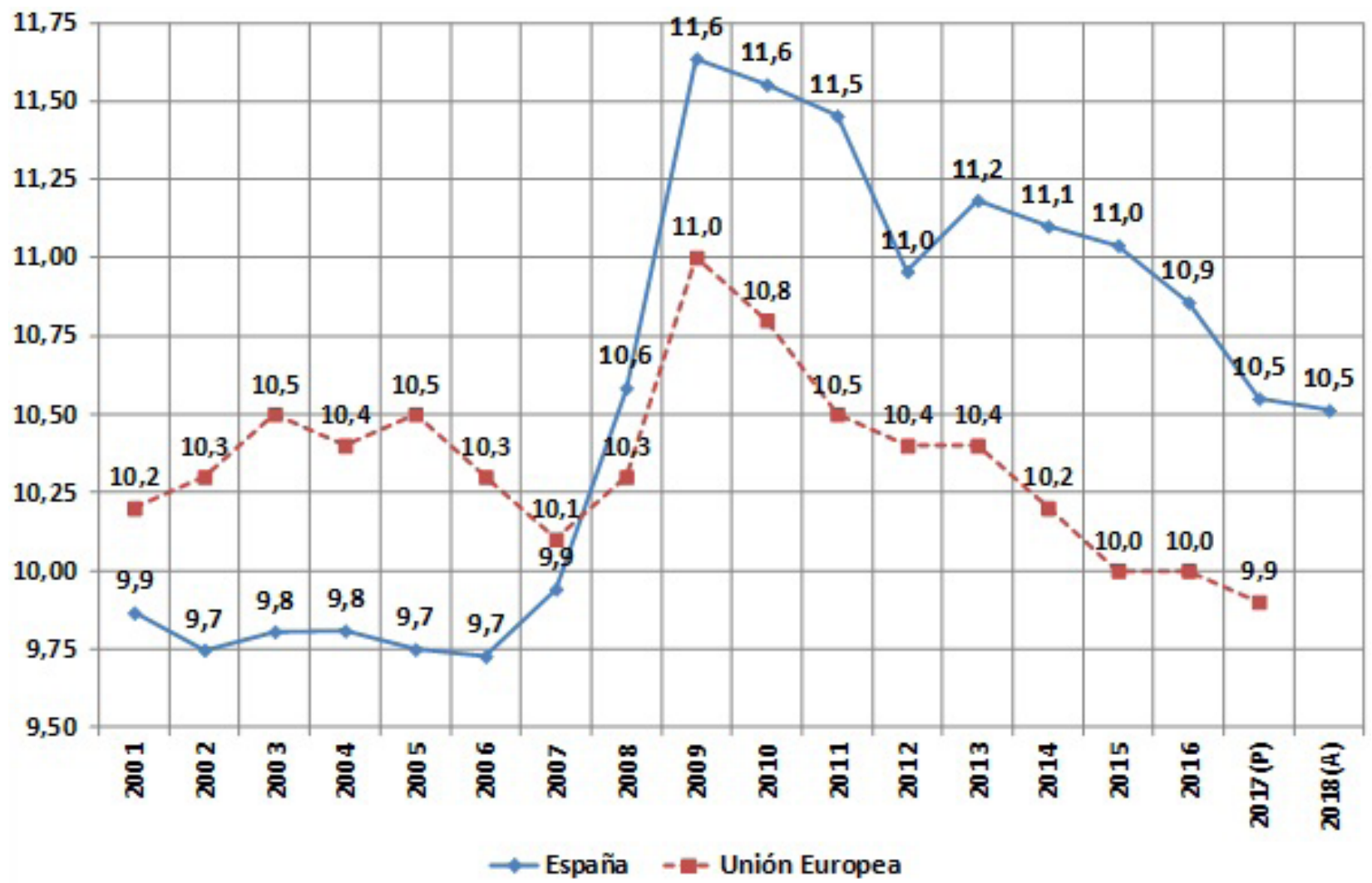

Fuente: Elaboración propia: Contabilidad Nacional (IGAE) y EUROSTAT.

\section{DISCUSIÓN Y PROPUESTAS}

Las diferencias entre las distintas estadísticas no prejuzgan la calidad de las fuentes y la utilización de cada una depende de los objetivos de cada investigación o del aspecto que se quiera analizar. En realidad, de fondo, la disonancia descrita es aparente puesto que todas ellas miden realidades distintas.

La disparidad de los resultados entre las distintas operaciones estadísticas proviene de la metodología empleada, principalmente del colectivo sobre el que recoge información, y del ámbito de referencia temporal. La objetividad de los datos no deriva de la fuente de información. El uso de registros administrativos es más adecuado para el estudio de las retribuciones y por la posibilidad de desegregación de los datos permite un análisis en profundidad del empleo en algunas administraciones.

Entre la Agencia Tributaria, que recoge a todos los que en algún momento de un año han trabajado en el sector público, y la Seguridad Social que presenta una media mensual en la que figuran únicamente los afiliados al régimen general de la Seguridad Social, hay una diferencia muy importante, en 2017 un millón de empleados suplementarios en la Agencia Tributaria, que se justifica plenamente por el número de empleados públicos que no pertenecían al régimen general de la Seguridad Social y por los que a lo largo del año dejan de trabajar, por fin de contrato, despido, excedencia, sanción, jubilación o fallecimiento, y que continúan en la estadística de la Agencia Tributaria y no en la Seguridad Social. 
Las diferencias entre la Encuesta de Población Activa (EPA) y el Boletín estadístico del personal al servicio de las administraciones públicas (BEPSAP), de media un $17,4 \%$, se justifican igualmente por los colectivos que recogen. En el BEPSAP no se incorporan los contratados por menos de seis meses en las CCAA, ni los empleados en administración institucional de las CCAA. Además, la referencia temporal de ambas estadísticas también es distinta, lo que igualmente afecta a los resultados. La EPA, que ofrece datos trimestralmente, tiene un carácter continuo, y figuran los que han trabajado en la semana de referencia de cada muestra, Mientras que el BEPSAP, que ofrece datos semestralmente, tiene un carácter estático referido al 1 de enero o al 1 de julio de cada año.

Si se quiere abarcar la totalidad del empleo público, cuantificar su número, analizar sus características sociales, o laborales, y realizar comparaciones internacionales o sectoriales con carácter general sólo se puede emplear la Encuesta de Población Activa. Por el contrario, para estudiar la distribución de las grandes categorías del empleo público (funcionarios, laborales, eventuales, etc.) o la distribución interna de los recursos humanos de la Administración General del Estado sólo es útil el BEPSAP del Registro Central de Personal.

Esta idea subraya las limitaciones técnicas y políticas de la información de las fuentes administrativas que se incorporan en el BEPSAP, entre las que el Registro Central de Personal sólo aporta sólo una parte del total del personal al servicio de las administraciones públicas. Y además pondera la calidad de las operaciones estadísticas del mercado de trabajo que permiten de manera homogénea, sistemática y objetiva estudiar el conjunto de la población activa tanto en España como en la Unión Europea.

Desde el punto de vista del gasto público por la amplitud de su serie temporal, por la desagregación territorial, o por la posibilidad de comparaciones internacionales y sectoriales, la fuente más relevante es Contabilidad Nacional. Si bien para estudiar la composición interna de los gastos de personal además puede acudirse a las estadísticas de liquidación presupuestaria y para profundizar en el sistema retributivo o en la estructura de la masa salarial de los ministerios a la Estadística de Retribuciones del Sector Público Administrativo de la AGE.

Si se quiere conocer las retribuciones percibidas por los empleados públicos individualmente considerados, cuya cuantía unida a las cotizaciones sociales abonadas por el empleador, debe ser igual al gasto de personal, la utilidad de una u otra estadística depende los objetivos del estudio.

El número de perceptores de la Agencia Tributaria, unidos a los de las agencias forales, corresponde fielmente al gasto de personal, de manera que una asociación directa entre empleados y remuneraciones debe referirse al colectivo de la Agencia Tributaria y a la remuneración de Contabilidad Nacional.

La Agencia Tributaria permite distinguir por género cada tramo retributivo y la Estadística salarial del empleo principal de la EPA, que no distingue género ni tipo de entidad, permite conocer el salario medio del empleo principal de los asalariados públicos, desagregado en cada decil de salario, y compararlo con el conjunto del sector privado. En ninguno de los dos casos tenemos información retributiva de los trabajadores individualmente considerados sobre variables esenciales como la edad, la antigüedad, la movilidad, o el tipo de administración en el que trabajan.

Como se ha señalado sobre el empleo público contamos con seis fuentes principales, todas ellas con características y resultados diferentes. ¿Esta disonancia es un problema? ¿Merece la pena tratar de resolverla? ¿Es viable? El desarrollo y la evaluación de las políticas públicas y desde luego la política de empleo público requieren información eficiente sobre el alcance de los recursos humanos.

Además la discordancia en la información sobre la contratación temporal o la falta de precisión sobre la distribución territorial de los empleados públicos, la escasa información sobre las desigualdades salariales de género, la dificultad para contabilizar los recursos humanos y su coste asignados a grandes políticas públicas, por señalar sólo otras cuatro cuestiones, justifican la necesidad de evaluar la viabilidad de una reforma de las estadísticas sobre empleo público.

Para mejorar y simplificar la información estadística sobre el empleo en el sector público se podría explorar la viabilidad de ampliar el modelo desarrollado con éxito en la estadística salarial de la EPA, lo que permitiría disponer de un sistema de información estadístico integral que vincule el registro de función públi$\mathrm{ca}$, las estadísticas laborales, los registros fiscales, y los de la seguridad social.

Para ello se podría considerar la posibilidad de volcar en la estadística del BEPSAP -función pública- la información recogida en los registros de la Seguridad Social y de las Agencias Tributarias, de manera que se consideren en el BEPSAP a todos los empleados públicos, y además complementar el cuestionario de la EPA con la información de dichos registros.

¿Cuántos empleados públicos hay en España? La respuesta efectivamente depende de la estadística a la que se acuda. Para clarificar la respuesta, se podría avanzar hacia una definición estadística común, 
que pudiera ser la que emplea la EPA, de forma que a estos efectos en el Plan Estadístico Nacional se defina como empleados públicos a los asalariados de las administraciones y del sector público institucional «que hayan trabajado incluso de forma esporádica u ocasional, al menos una hora a cambio de un sueldo, salario u otra forma de retribución conexa, en metálico o en especie» lo que supone una modificación importante en la estadística del BEPSAP que podría obtenerse bien ampliando la información que se requiere de la Comunidades Autónomas, bien combinando el registro de función pública con los de la Agencia Tributaria y sobre todo con los de la Seguridad Social, y realizar una explotación temporal -la semana de referencia- o la media análoga a la de la EPA, o partir de la idea de media mensual con la que trabaja la Seguridad Social. Esta aproximación permitiría presentar información referida al 1 de enero o al 1 de julio, y además publicar en el BEPSAP información mensual, trimestral y anual, que también serviría de referencia para la EPA.

¿Cuántos son los empleados asignados a las grandes políticas públicas? La cuestión no tiene una respuesta directa. Si se acude a la clasificación funcional de los gastos que publica la IGAE en Contabilidad Nacional, conoceremos el gasto en personal pero Contabilidad Nacional no añade información sobre los asalariados. Tal vez pueda incorporarse en el Plan Estadístico Nacional una operación de síntesis que trate de dar respuesta sistemática y homogénea a esta cuestión. Algunas lagunas como la falta de información directa sobre el empleo público en la sanidad son realmente sorprendentes. Y desde luego existe la dificultad adicional de integrar lo que corresponde a cada política pública, sobre todo cuando algunas de ellas son transversales y están afectadas por varios departamentos.

¿Cuántos empleados hay en cada ministerio? La respuesta parece sencilla, el BEPSAP publica semestralmente una relación detalladas de empleados de cada ministerio. Sin embargo si buscamos una seria temporal, la cuestión es más compleja porque la desagregación por departamentos depende de la organización siempre cambiante de la estructura ministerial. Tal vez podría pensarse en añadir una clasificación funcional o por ramas de actividad, que fuera estable y permitiera relacionarla con el gasto.

¿Cuál es la diferencia salarial de hombres y mujeres en el empleo público? La respuesta no es sencilla. Puede acudirse a los datos publicados por la Agencia Tributaria, pero nos encontraremos con un concepto amplio de empleados públicos, los perceptores de renta en algún momento del año. Y si acudiéramos a la Encuesta Salarial de la EPA no encontraremos información del empleo público desagregada por género. Parece necesario añadir la variable de género en la información sobre el salario medio de los asalariados del sector público y privado.

La respuesta a otras cuestiones como ¿cuál es la distribución territorial del empleo público?, ¿en cuál administración trabajan?, o ¿cuántos empleados públicos tienen un contrato temporal? Y ¿cuál es la retribución efectiva que cobran los empleados públicos?, depende también de la estadística a la que acudamos. Para contestar a estas y a otras preguntas semejantes se debería explorar la viabilidad de mejorar las operaciones estadísticas sobre el empleo y las retribuciones en el sector público y avanzar hacia un modelo de información estadístico integral.

El tamaño importa, reflexionaba en su última ${ }^{34}$ lección la profesora Olías de Lima, y para comprobarlo es imprescindible mejorar nuestra manera de medir.

\section{REFERENCIAS BIBLIOGRÁFICAS}

AGENCIA TRIBUTARIA (2016): Mercado de trabajo y pensiones en las fuentes tributarias. Madrid: Agencia Tributaria. Recuperado el 1 de diciembre de 2017, de: https://www.agenciatributaria.es/AEAT.internet/datosabiertos/catalogo/ hacienda/Mercado_de_Trabajo_y_Pensiones_en_las_Fuentes_Tributarias.shtml.

AGENCIA TRIBUTARIA (2017): Mercado de trabajo y pensiones en las fuentes tributarias. Madrid: Agencia Tributaria. Recuperado el 1 de diciembre de 2017, de: https://www.agenciatributaria.es/AEAT.internet/datosabiertos/catalogo/ hacienda/Mercado_de_Trabajo_y_Pensiones_en_las_Fuentes_Tributarias.shtml.

ARENILLA SÁEZ, M.; DELGADO RAMMOS, D. (2014): “¿Hay muchos empleados públicos en España? Eficiencia y efectividad en el contexto de la OCDE”, en Revista de Administración Pública, núm. 193, págs. 297-334.

BAENA DEL ALCÁZAR, M. (1985): Curso de Ciencia de la Administración. Madrid: Tecnos.

COMISIÓN PARA LA REFORMA DE LA ADMINISTRACIÓN (CORA) (2013): Reforma de las Administraciones Públicas. Madrid: Ministerio de Hacienda y Administraciones Públicas y Ministerio de la Presidencia. URL: https:// administracion.gob.es/pag_Home/ca/dam/jcr:4c4e8573-6220-4b6a-9397-8f95e566b42a/INFORME-LIBRO.pdf.

34 A propósito de la Administración: el tamaño sí importa. Departamento de Ciencia Política y de la Administración, Universidad Complutense de Madrid, 8 de mayo de 2019. 
GAPP. Nueva Época - N. ${ }^{\circ}$ 23, mayo-octubre 2020 - ISSN: 1989-8991 - DOI: 10.24965/gapp.i23.10686 - [Págs. 20-44]

Las fuentes de información sobre el empleo público en España: revisión, diagnóstico y propuestas de cambio

José María de Luxán Meléndez

HERNÁDEZ DE COS, P.; MORAL-BENITO, E.; PÉREZ, J. J. (2016): "El empleo y los salarios públicos durante la crisis: análisis desde una perspectiva internacional y regional”, en Papeles de Economía Española, núm. 147, págs. 68-91.

INSTITUTO NACIONAL DE ESTADÍSTICA (INE) (2014): Estadística de Flujos de la Población Activa. Metodología para el cálculo del flujo en valores absolutos. Madrid: INE. URL: https://www.ine.es/inebaseDYN/flujos30310/docs/ metoflujos_valores_absolutos.pdf.

INSTITUTO NĀCIONALL DE ESTADÍSTICA (INE) (2016): El empleo de las personas con discapacidad. Explotación de la Encuesta de Población Activa y de la Base Estatal de Personas con discapacidad. Metodología y descripción de la operación. Madrid: INE. URL: https://www.ine.es/metodologia/t22/t2230320.pdf.

INSTITUTO NACIONAL DE ESTADÍSTICA (INE) (2017): Evaluación de la calidad de los datos de la Encuesta de Población Activa. Año 2017. Madrid: INE. URL: https://www.ine.es/en/docutrab/eval_epa/evaluacion_epa17_en.pdf.

INSTITUTO NACIONAL DE ESTADÍSTICA (INE) (2017): Encuesta de Población Activa. Metódología 2005. Descripción de la encuesta, definiciones e instrucciones para la cumplimentación del cuestionario. Madrid: INE. URL: https://www.ine.es/daco/daco43/resumetepa.pdf.

INSTITUTO NACIONAL DE ESTADISTICA (INE) (2017): Cuentas Trimestrales no financieras de los sectores institucionales. Metodología. Madrid: INE. Recuperado el 1 de diciembre de 2017, de: https://www.ine.es/dyngs/ INEbase/es/operacion.htm?c=Estadistica_C\&cid=1254736165305\&menu=metodologia\&idp $=1254735576581$.

INSTITUTO NACIONAL DE ESTADÍSTICA (INE) (2017): Instituto Nacional de Estadística. El Salario del Empleo Principal en la Encuesta de Población Activa. Explotación estadística de los Registros de la Seguridad Social y de las Agencias Tributarias. Madrid: INE. URL: https://www.ine.es/metodologia/t22/nota_epa_decil.pdf.

INSTITUTO NACIONAL DE ESTADÍSTICA (INE) (2017): Inventario de Operaciones Estadísticas. Madrid: INE. URL: https://www.ine.es/dyngs/IOE/index.htm.

INSTITUTO NACIONAL DE ESTADÍSTICA (INE) (2019): Revisión estadística 2019 de las operaciones de Contabilidad Nacional del INE. Madrid: INE. URL: https://www.ine.es/normativa/leyes/cse/cambio_meto_ Revisi\%C3\%B3nContabilidad2019.pdf.

INTERVENCIÓN GENERAL DE LA ADMINISTRACIÓN DEL ESTADO (IGAE) (2016): Personal al servicio del Sector público Estatal 2016. Madrid: IGAE. URL: https://www.igae.pap.hacienda.gob.es/sitios/igae/es-ES/ Contabilidad/informacionEconomica/Documents/20170530LibroSPE2016.pdf\#search=personal.

JORDANA, J.; RAMIÓ, C. (2005): "Gobierno y Administración", en CARRERAS, A.; TAFUNELL, X. (eds.): Estadísticas históricas de España: Siglos XIX-XX. Bilbao: Fundación BBVA (2. ${ }^{a}$ ed.)

JUNQUERA GONZÁLEZ, J.; GONZÁLEZ-HABA GUISADO, V. M.; IPARRAGUIRRE AMIANO, P.; SANTAMARÍA PÉREZ, P. (1974): Evolución y previsión de efectivos en la Administración Civil del Estado. Madrid: Presidencia del Gobierno.

LUXÁN MELÉNDEZ, J. M. (2016): "El impacto de la crisis en las retribuciones del Sector Público", en Cuadernos de Gobierno y Administración Pública, vol. 3, núm. 2, págs. 143-169. DOI: https://doi.org/10.5209/CGAP.55085.

LUXÁN MELÉNDEZ, J. M. (2018): "Brecha salarial o discriminación laboral. Retribuciones y carrera profesional de las mujeres en el sector público", en Derecho de las Relaciones Laborales, núm. 3, págs. 287-304.

LUXÁN MELÉNDEZ, J. M. (2019): "Las políticas de empleo público en España (1996-2017): diagnóstico y propuestas para su modernización y eficiencia", en Revista del Ministerio de Empleo y Seguridad Social. Economía y Sociología, núm. 141.

LUXÁN MELÉNDEZ, J. M. (2019b): "La ruptura del contrato de lealtad. Evolución del empleo científico-técnico en el Sector Público español”, en Cuadernos de Gobierno y Administración Pública, vol. 6, núm. 2, págs. 71-91. DOI: https://doi.org/10.5209/cgap.65911.

MARTÍNEZ, M.; PÉREZ, J. (2017): "La evolución del empleo de las Administraciones Públicas en la última década", en Boletín Económico, núm. 4. Madrid: Banco de España.

MONTESINOS, A.; PÉREZ, J.; RAMOS, R. (2014): "El empleo de las Administraciones Públicas en España: Caracterización y evolución durante la crisis", en Documentos Ocasionales, núm. 1.402. Madrid: Banco de España.

OLÍAS DE LIMA, B. (coord.) (1995): Gestión de Recursos Humanos en las Administraciones Públicas. Madrid: Editorial Complutense.

OLÍAS DE LIMA, B. (2006): Manual de organización administrativa del Estado. Madrid: Síntesis.

OLMEDA, J. A., PARRADO, S.; COLINO, C. (coords.) (2017): Las Administraciones Públicas en España. Valencia: Tirant lo Blanch (2. ${ }^{\text {a ed. }}$ ).

PARRADO, S. (2017): "Los empleados de la Administración General del Estado”, en OLMEDA, J. A., PARRADO, S.; COLINO, C. (coords.): Las Administraciones Públicas en España, pág. 478 Valencia: Tirant lo Blanch (2. ${ }^{a}$ ed.).

REGISTRO CENTRAL DE PERSONAL (VARIOS AÑOS): Boletín estadístico del personal al servicio de las Administraciones Públicas. Registro Central de Personal. Madrid: Ministerio de Hacienda y Función Pública. URL: https://www.mptfp.gob.es/portal/funcionpublica/funcion-publica/rcp/boletin.html.

REGISTRO CENTRAL DE PERSONAL (2018): Boletín estadístico del personal al servicio de las Administraciones Públicas. Registro Central de Personal. Madrid: Ministerio de Política Territorial y Función Pública. URL: https:// www.mptfp.gob.es/dam/es/portal/funcionpublica/funcion-publica/rcp/boletin/Boletines/Bol_Semestral_201807.pdf. 